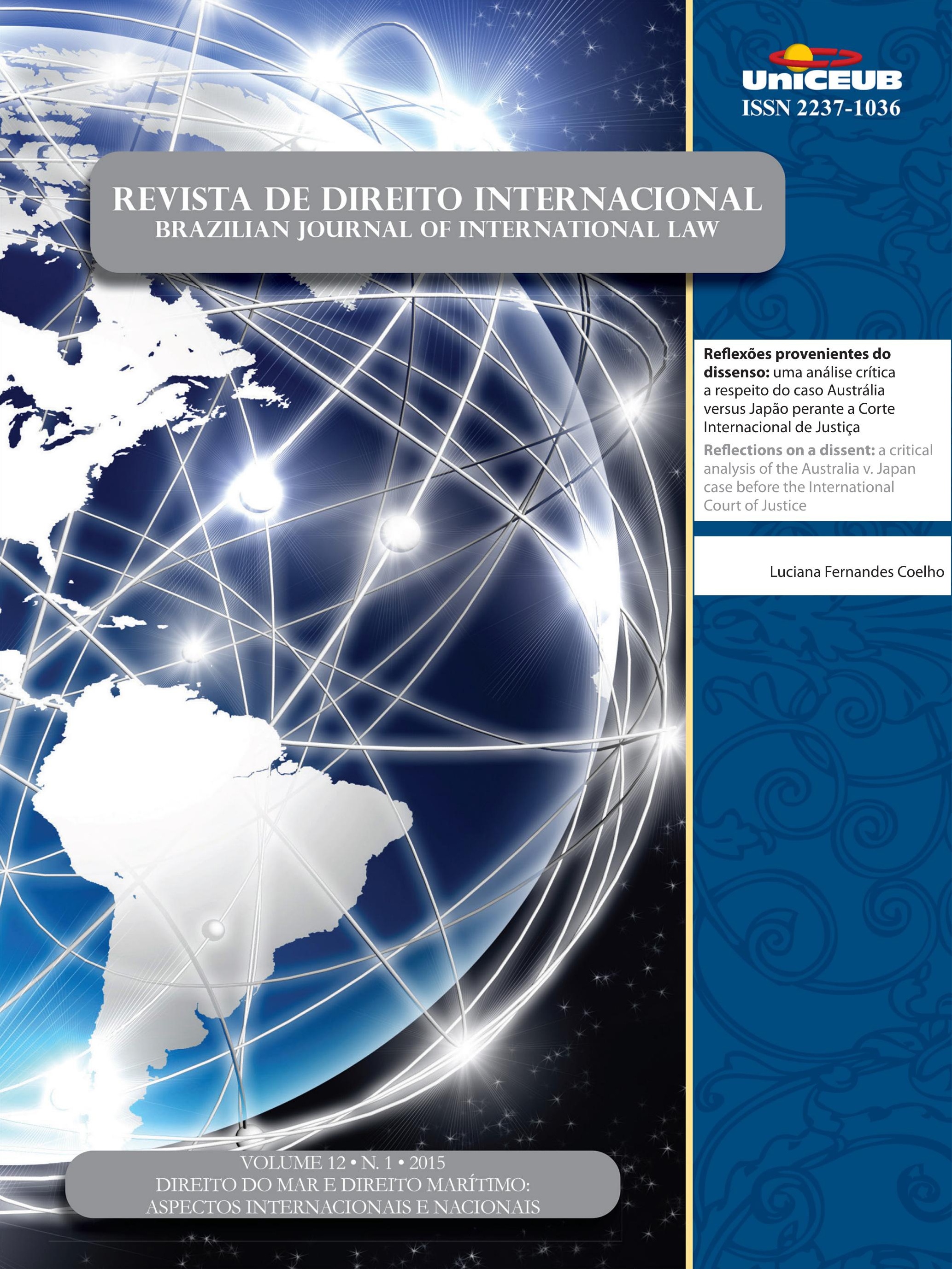




\section{Sumário}

\section{Crônicas}

CRôNICAS DA ATUALIDADE do DiREITO INTERNACIONAL ........................................................ 2

Nitish Monebhurrun (org.)

Towards a european regulation of the importation of conflict minerals?..... 2

Nitish Monebhurrun

Keeping up with the terrorists: the EU's proposed Passenger Name Records (PNR) Directive \& european security

Eshan Dauhoo

A histórica reaproximação de Cuba e EUA

Erika Braga

A contextualização da atual reivindicação da Grécia para receber indenizações por atos da Alemanha durante a Segunda Guerra Mundial . .10

Natália da Silva Gonçalves

José Eduardo Paiva Miranda de Siqueira

Crônicas da jurisprudência do Direito Internacional (CIJ/ITLOS): Decisões da Corte Internacional de Justiça e do Tribunal Internacional Sobre o Direito do Mar .14

Nitish Monebhurrun (Org.)

Corte Internacional de Justiça

Estudo da decisão da Corte Internacional de Justiça no caso Croácia v. Servia (03/02/2015) .14

Liziane Paixão Silva Oliveira e Maria Edelvacy Marinho

Questões relacionadas com a apreensão e detenção de certos documentos e dados: (Timor Leste c. Austrália) - O reconhecimento do retorno de uma relação amigável entre Timor-Leste e Austrália e a nova decisão da CIJ, 6 de maio de 2015 . 20

Gleisse Ribeiro Alves

Tribunal Internacional sobre Direito do Mar

Caso da delimitação da fronteira marítima entre o Gana e a Costa do Marfim no Oceano Atlântico: medidas cautelares $(25 / 04 / 2015)$

Nitish Monebhurrun

Comentário à Opinião Consultiva 21 do Tribunal Internacional para o Direito Do Mar [02/04/2015] (Responsabilidade do Estado de Bandeira pela pesca ilícita, não declarada ou não regulamentada) ...............25

Carina Costa de Oliveira 
CRÔNICAS DO DIREITO INTERNACIONAL DOS INVESTIMENTOS

Nitish Monebhurrun (Org.)

A inclusão da responsabilidade social das empresas nos novos Acordos de Cooperação e de Facilitação dos Investimentos do Brasil: uma revolução 33

Nitish Monebhurrun

\section{O Direito do Mar Perante as JuRisdições INTERnacionais}

CoAstal States' Rights IN THE MARITIME AREAS UNDER UNCLOS .40 Tullio Treves

TACKling illegal, unregulated And unReported Fishing: THE ITLOS Advisory OpINION on Flag State Responsibility for IUU fishing AND THE PRINCiple of DUE DiligenCE ...50 Victor Alencar Mayer Feitosa Ventura

REFLEXões PROVENIENTES do DisSENSO: UMA ANÁLISE CRÍtica A RESPEITO do CASO Austrália versus Japão Perante a Corte InTERnacional de JustiçA .......................................68 Luciana Ferna ndes Coelho

Os TRATADOS INTERNACIONAIS DE DIREITO DO MAR E SEUS EFEITOS SOBRE TERCEIROS ESTADOS ..... 86 Tiago V. Zanella

\section{InStRumentos JURÍdicos PARA A GeStÃo do MAR}

OS LIMITES DOS TERMOS BEM PÚBLICO MUNDIAL, PATRIMÔNIO COMUM DA HUMANIDADE E BENS COMUNS PARA DELIMITAR AS OBRIGAÇÕES DE PRESERVAÇÃO DOS RECURSOS MARINHOS 109 Carina Costa de Oliveira e Sandrine Maljean-Dubois

Os limites do PLANEJAMENTO DA OCUPAÇÃo SUSTENTÁVEL DA ZONA COSTEIRA BRASILEIRA ... 126 Carina Costa de Oliveira e Luciana Coelho

CORRENDO PARA O MAR NO ANTROPOCENO: A COMPLEXIDADE DA GOVERNANÇA DOS OCEANOS E A ESTRATÉGIA BRASILEIRA DE GESTÃO DOS RECURSOS MARINHOS 
A comissão de limites da Plataforma continental (CLPC) E Os DESAFios Na delineaÇÃo DAS PLATAFORMAS CONTINENTAIS ESTENDIDAS................................................... 170

Alexandre Pereira da Silva

\section{A PROTEÇÃo DO MEIO AMBIENTE MARINHO}

O gRANDE JOGo do ÁrTiCo: REFLEXões COM BASE NA PERSPECTIVA DE EXPLORAÇão ECONÔMICA

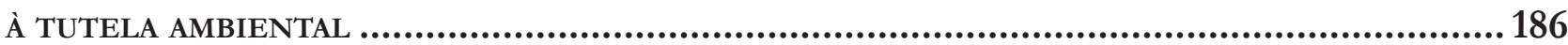

Fernando Rei e Valeria Cristina Farias

Instrumentos Públicos e Privados para a reparação do dano ambiental causado por DERRAMAMENTO DE ÓLEO NO MAR SEM ORIGEM DEFINIDA: AS MANCHAS ÓRFÃS

Renata Brockelt Giacomitti e Katya R. Isaguirre-Torres

O DIREITO INTERNACIONAL PRIVADO E A RESPONSABILIDADE CIVIL EXTRACONTRATUAL POR DANOS AMBIENTAIS CAUSADOS POR TRANSPORTES MARÍTIMOS À LUZ DO DIREITO BRASILEIRO ....... 217 Inez Lopes

A NECESSIDADE DE REPENSAR OS MECANISMOS DE RESPONSABILIDADE AMBIENTAL EM CASO DE riscos de VAZamento de PETRóleo Na Zona Econômica Exclusiva do BrasiL

Marcelo D. Varella

\section{Problemáticas do Direito Marítimo}

A FisCALIZAÇão SANitÁRIA DAS EMBARCAÇÕES EM ÁGUAS JURISDICIONAIS BRASILEIRAS: NOTAS aCERCA da (IN)efetividade da Súmula 50 da AGU

Joedson de Souza Delgado e Ana Paula Henriques da Silva

A IMO E A REPRESSÃo AO ROUBO ARMADO CONTRA NAVIOS: DA RETÓRICA INTERNACIONAL À COOPERAÇÃO REGIONAL

André Panno Beirão e Charles Pacheco Piñon

\section{O Direito do Mar diante da Pirataria}

O DIREITO INTERNACIONAL EM FACE DA PIRATARIA EM ALTO-MAR: UMA PERSPECTIVA CRÍTICA.289 Maiquel Ângelo Dezordi Wermuth e Rafaela Correa 
Pirataria marítima: A EXPERIÊnCIA Somália

Eduardo Augusto S. da C. Schneider

\section{Temas Gerais}

DRAWING THE LINE: ADDRESSING ALLEGATIONS OF UNCLEAN HANDS IN INVESTMENT ARBITRATION*

Mariano de Alba

Para Que Serve a história do Direito internacional?

George Rodrigo Bandeira Galindo

As interferências entre a Política Externa e de Segurança Comum Europeia (Pesc) e O DiREITO DAS NaÇões UNIDAS

Leonardo de Camargo Subtil

Introdução Às regras de aplicaÇão da Convenção da ONU Sobre Contratos de ComPRA E VENDA INTERNACIONAL DE MERCADORIAS E O DIREITO INTERNACIONAL PRIVADO BRASI-

LEIRO 380

Paul Hugo Weberbauer e Eugênia Cristina Nilsen Ribeiro Barza

A REgulaÇÃo das EMPRESAS TRANSNACIONAIS ENTRE AS ORDENS JURÍDICAS ESTATAIS E NÃO ESTATAIS.

Mateus de Oliveira Fornasier e Luciano Vaz Ferreira

OUtLAWING HATE SPEECH IN DEMOCRATIC STATES: THE CASE AGAINST THE INHERENT LimitAtions doctrine concerning Article 10 (1) of the European Convention on Human

Rights 416

Stefan Kirchner 


\title{
Reflexões provenientes do dissenso: uma análise crítica a respeito do caso Austrália versus Japão perante a Corte Internacional de Justiça*
}

\author{
Reflections on a dissent: a critical analysis \\ of the Australia v. Japan case before the \\ International Court of Justice
}

Luciana Ferna ndes Coelho**

\section{Resumo}

A Corte Internacional de Justiça apreciou pedido australiano contra o Japão por este ter supostamente concedido licença especial ao Projeto JARPA II sem que este tivesse fins científicos, conforme pressupõe o artigo VIII da Convenção Internacional sobre Regulação de Pesca às Baleias. Este trabalho tem por objetivo analisar criticamente a sentença do caso. Para tal, primeiramente, serão apresentadas algumas informações relevantes que contextualizam essa controvérsia. Em seguida, problematizar-se-á o mérito da sentença, enfocando dois aspectos: a metodologia do critério de exame (standard of review) e a ausência de pronunciamento da Corte sobre o conceito de pesquisa científica marinha (talvez inverter). Para tal, emprega-se o método dialético de contraposição entre os argumentos contidos na sentença e os formulados nas opiniões divergentes. A originalidade do artigo está no fato de analisar, criticamente, um caso recente, em que o Tribunal se encontra diante de uma controvérsia que envolve questões de mérito cientifico. Para tal, utilizou, de forma inédita, metodologia de análise, já empregada pela OMC em casos semelhantes, o stadard of the review. Ao final, observa-se que essa ferramenta metodológica gerou argumentos confusos, incoerentes e questionáveis, consequentemente, ao contrário de o julgamento gerar maior proteção à biodiversidade marinha, possibilitará que o Japão continue a realizar a atividade de pesca baleeira. Caso o Tribunal tivesse adotado postura sistêmica, utilizando-se das construções interpretativas realizadas por outros tribunais ou convenções internacionais a respeito da pesquisa científica marinha, a decisão poderia produzir maior estabilidade jurídica e proteção à biodiversidade.

Palavras-chave: Pesca. Baleias. Pesquisa científica. Marinha.

\section{Abstract}

The International Court of Justice tried an Australian request against Japan for having granted special license to JARPA II project, which supposedly was not for scientific purposes, as required by Article VIII of the International Convention for the Regulation of Whaling. This paper aims 
to analyze critically this trial. For that, first we present some background elements that might be help to understand the dispute. After that, we will analyze the merits of the decision focusing on two aspects: the methodological criteria adopted, standard of review, and the absence of the Court on defining marine scientific research. To do this, we employ the dialectic method, contrasting the arguments made in the judgment with those presented in the dissent opinions. The originality of the article lays in the fact that it analyses critically a recent case, wherein the Court faced scientific issues. For that purpose, the Court used a novel methodology called standard of review, already employed by WTO in similar cases. Finally, it is noticed that this methodology produced confusing, inconsistent and questionable arguments, therefore, on the contrary of providing more protection to marine biodiversity, the case will allow Japan to continue the whaling activity. If the Court had adopted a systemic approach, using the guidelines made by other courts or international conventions concerning the marine scientific research, the decision could have produced a greater legal stability and protection to biodiversity.

Keywords: Whaling. Whales. Scientific research.

\section{INTRODUÇão}

A Corte Internacional de Justiça - CIJ é identificada por alguns como o Tribunal Mundial. Para além das discussões doutrinárias invocadas por essa percepção, fato é que suas decisões são vinculantes, sem existir instancia recursal de suas decisões. Essa constatação incita reflexões como, por exemplo, a observação do poder atinente a esse tribunal e a responsabilidade inerente às teses defendidas por cada juiz, haja vista as proporções das consequências provenientes de suas decisões. No entanto, isso torna suas decisões infalíveis? Seriam elas impassíveis de críticas? Os juízes da Corte possuem expertise para apreciar todas as controvérsias apresentadas a eles?

Por óbvio que não. É notório que a tese da existência de um juiz Hércules, totalmente imparcial, que consegue abandonar suas percepções culturais e pessoais ao julgar, já está superada. É certo também que inexiste norma hipotética fundamental perfeita, limpa, branca de vícios e sem passado valorativo que mereça ser desconsiderado pelo órgão julgador no momento da aplicação da norma. Assim, deve ser pressuposto que cada argumento, cada posição, cada voto é imbuído da percepção do juiz, de sua interpretação e ideologia, de sua vivência e trajetória. No entanto, para que uma decisão jurídica seja socialmente aceita, ela deve ser imbuída de argumentos e embasada em provas suficientes para convencer à sociedade - nesse caso, poder-se-ia dizer "a sociedade dos Estados" - de sua razoabilidade.

Nesse contexto, na contramão da euforia demonstrada por alguns movimentos ambientalistas por ter o primeiro caso que versa sobre a caça às baleias julgado por tribunal internacional, o presente artigo se propõe a problematizar alguns posicionamentos, silêncios e contradições existentes na sentença do caso Whaling in the Antartic (Australia vs. Japan, New Zeland Intervening) — em especial, os decorrentes da omissão da Corte em relação ao conceito de pesquisa científica marinha e da adoção da metodologia do critério de exame, ${ }^{1}$ que, ao contrário do que os movimentos ambientalistas esperam, podem ter enfraquecido a legitimidade e a segurança jurídica da decisão.

Para tanto, realizar-se-á contraposição entre as teses acolhidas na sentença e os argumentos levantados nos votos divergentes e na doutrina. $\mathrm{O}$ estudo não pretende apontar se o Japão realiza caça de cunho comercial às baleias ou se a quantidade de baleias caçadas é ou não razoável em relação aos objetivos do Programa JARPA II. O ponto fulcral deste artigo consiste em demonstrar como a ferramenta de análise empregada pela Corte, que atesta abertura da $\mathrm{CIJ}$ ao funcionamento de outros tribunais, gerou decisão confusa e contraditória.

No caso supramencionado, a Corte foi incitada a decidir se o governo japonês violou: (i) a obrigação de manter a quota zero de caça às baleias com escopo comercial; (ii) a obrigação de não realizar caça comercial às baleias fin no Santuário Baleeiro do Oceano Austral (Southern Ocean Sanctuary); (iii) a moratória em relação à caça, captura e matança de baleias, exceto as baleias minke, por navios-fábrica ou por navios baleeiros ligados a navios-fábricas. A Austrália também solicitou que a finalidade da Segunda Fase do Programa Japonês de Pesquisa sobre as Baleias na Antártica sob Licença Especial (Seconde Phase of Japanese Whale Research Program under Special Permit in the

1 O termo "critério de exame" é uma tradução livre de "standard of the review", no original em inglês, e "critère d'examen", no original em francês. 
Antarctic - JARPA II) fosse declarada como diversa da investigação científica, ensejando a revogação de sua licença especial, e de qualquer outra que não tenha por fim realizar pesquisa científica. As obrigações violadas têm respaldo na Convenção Internacional para Regulação da Pesca a Baleias (International Convention for the Regulation of Whaling-ICRW) e em seu Cronograma anexo; na Convenção sobre o Comércio Internacional de Espécies da Fauna e Flora Selvagens Ameaçadas (Convention on International Trade in Endangered Species of Wild Fauna and Flora - CITES); e na Convenção sobre Diversidade Biológica (Convention on Biological Diversity $-C B D)^{2}$

O caso singulariza-se porque a Corte foi instada a apreciar questões de cunho eminentemente científico, ${ }^{3}$ ou seja, a classificação do Programa Jarpa II como pesquisa cientifica marinha - ou pesquisa marinha com finalidade científica - e, consequentemente, a legalidade da expedição de sua licença especial. Ademais, essa foi a primeira vez que a temática da caça às baleias com finalidade científica extrapolou os limites da Comissão Internacional para a Caça às Baleias (órgão da ICRW) e foi discutida em Tribunal Internacional. Outro aspecto que chama a atenção consiste na repercussão social e a sensibilidade que a temática da caça às baleias produz em razão do histórico de lutas da sociedade civil contra essa atividade, além das questões culturais, mitológicas, religiosas e econômicas envolvidas. Essa complexidade reflete-se na existência de somente um ponto do dispositivo em que houve unanimidade entre os juízes da Corte, qual seja, a competência do Tribunal para julgar o feito.

2 INTERNATIONAL COURT OF JUSTICE. 2014. 31 March. Whaling in the Antarctic Australia v. Japan: New Zealand intervening: mérits. Disponível em: <http://www.CIJ-cij.org/docket/index.php?p $1=3 \& \mathrm{p} 2=3 \& \mathrm{k}=64 \& \mathrm{case}=148 \& \operatorname{code}=\mathrm{aj} \& \mathrm{p} 3=4>$. Acesso em: 20 dez. 2014. p. 17.

3 Parte da doutrina identifica o litígio como uma "disputa científica", em que fatos, conhecimentos ou entendimentos científicos são necessários para a decisão. Esse tipo de controvérsia passou a ganhar notoriedade e a atrair a atenção dos juristas com base nos casos EC-Hormones e EC-Approval and Marketing of Biotech Products, julgados pelo órgão de apelação da OMC (cf. FOSTER, Caroline. Motivations and methodologies: was Japan's Whaling programme for purposes of scientific research? In: SIMPÓSIO WHALING IN THE ANTARCTIC: THE ICJ JUDGMENT AND ITS IMPLICATION, 2014, Kobe. Presentation Files and Papers... Kobe: Kobe University, 2014. Disponível em: <http://www.edu.kobe-u.ac.jp/ilaw/en/whaling_docs/paper_Foster.pdf>. Acesso em: 10 jan. 2015; FOSTER, Caroline. Public opinion and the interpretation of the World Trade Organisation's Agreement on Sanitary and Phytos Anitary Measures. Journal of International Economic Law, v. 11, n. 2, p. 427-458, Fev. 2008. Disponível em: <http://jiel.oxfordjournals.org>. Acesso em: 10 maio 2015. doi:10.1093/jie l/jgn011. p. 427-458.
Nesse contexto, o artigo será dividido em dois tópicos. O primeiro é majoritariamente descritivo, nele será apresentado o pano de fundo do caso, haja vista que, como pôde ser observado acima, a controvérsia envolve o conhecimento de Convenções e provisões jurídicas bem específicas, logo, para ser possível problematizar o caso, é necessário antes entendê-lo. Nesse ínterim, enfocar-se-á no histórico de criação da ICRW, da decretação da moratória de caça às baleias e a interpretação do artigo VIII da Convenção; serão apresentados os Projetos JARPA I e JARPA II; e como foi feita a admissibilidade do caso perante a CIJ. No segundo tópico, problematizar-se-á a metodologia empregada pelo Tribunal para reavaliar a licença especial concedida pelo Japão ao projeto, enfoque especial será dado às críticas à utilização dessa ferramenta hermenêutica e à prejudicialidade ao julgado pelo fato de a Corte ter se esquivado de definir ou estabelecer critérios para a atividade de pesquisa científica marinha. Ao longo da exposição dos argumentos considerados pela CIJ, será realizada contraposição com as teses esposadas nos votos divergentes e na doutrina.

\section{O BACKGROUND}

A sentença da CIJ está estruturada em quatro momentos. No primeiro, a Corte expôs, em ordem cronológica, os procedimentos realizados pelas partes e as alegações trazidas por cada uma a fim de apresentar e defender suas alegações. A seguir, antes de apreciar o feito, o Tribunal estabeleceu sua competência para julgá-lo. Então, adentrou ao mérito e foi construída a argumentação para responder aos pedidos formulados pela Austrália. Por fim, a Corte dispôs sobre as violações cometidas pelo Japão e quais medidas devem ser adotadas para saná-las.

Inicialmente, foi realizada uma retrospectiva dos principais momentos processuais do caso e das alegações realizadas por cada parte, comprovando a observância do princípio do contraditório. Nessa oportunidade, cumpre ressaltar, que restou claro, por exemplo, os elementos que embasaram o pedido de intervenção realizado pela Nova Zelândia e sua posterior aceitação. ${ }^{4}$

4 Em artigo apresentado no Centro de Direito Internacional da Universidade de Kobe, Tamada argumentou que o ingresso da Nova Zelândia no processo como interessado (ou interveniente) e não como parte não foi um acaso, mas uma estratégia processual entre 
A competência do Tribunal para analisar o feito parece óbvia, pois tanto a Austrália quanto o Japão e a Nova Zelândia ratificaram a cláusula facultativa de jurisdição obrigatória, segundo disposto no artigo 36.2 do Estatuto da Corte. Ocorre que a Austrália realizou reserva em relação a disputas afeitas à delimitação de zonas marítimas, incluindo o mar territorial, a zona econômica exclusiva e a plataforma continental, ou provenientes ou relacionadas à explotação de alguma área em disputa ou adjacente a qualquer zona marítima pendente de delimitação. Diante disso, o Japão alegou que as atividades realizadas pelo projeto JARPA II ocorrem no Santuário Baleeiro australiano, que se insere em área reivindicada pela Austrália como parte de sua Zona Econômica Exclusiva - ZEE e aonde realizam atividade de explotação; logo, essa hipótese configura a reserva feita pela Austrália. ${ }^{5}$

Em contrapartida, a parte demandante argumentou que a reserva somente seria aplicável a casos que tivessem por objeto a discussão da delimitação da zona econômica exclusiva, o que não seria essa hipótese. Esse entendimento foi acolhido de forma unânime por todos os juízes da CIJ que, realizando referência aos casos $A n$ glo-Iranian Oil Co. (United Kingdom v. Iran) e Fisheries Jurisdiction (Spain v. Canada), entenderam que a controvérsia não tinha como objeto a delimitação da Zona Econômica Exclusiva - ZEE australiana ou mesmo a explotação de atividade exercida na ZEE. ${ }^{6}$ Note-se que essa

esse país e a Austrália a fim de afastar a aplicação do art. 31(5) do Estatuto da ICJ de modo que o juiz neozelandês membro da Corte não fosse declarado suspeito e a Austrália ainda tivesse garantido o seu direito de nomear um juiz ad hoc. O Professor também demonstrou outros prejuízos ao Japão resultantes do desequilíbrio processual entre as partes e da pouca experiência do país, litigando perante a CIJ, situações que não são aptas a desmerecer o julgamento, mas comprovam que o conhecimento do funcionamento de um tribunal internacional é decisivo para definir a melhor estratégia processual a ser seguida e rompe com a ilusão acrítica de isonomia plena entre as partes. Cf: DAI, Tamada. Unfavourable but unavoidable procedures: procedural aspects of the whaling case. In: SIMPÓSIO WHALING IN THE ANTARCTIC: THE ICJ JUDGMENT AND ITS IMPLICATION, 2014, Kobe. Presentation Files and Papers... Kobe: Kobe University, 2014. Disponível em: <http://www.edu.kobe-u.ac.jp/ ilaw/en/whaling_sympo2014.html>. Acesso em: 10 jan. 2015.

5 INTERNATIONAL COURT OF JUSTICE. 2014. 31 March. Whaling in the Antarctic Australia v. Japan: New Zealand intervening: mérits. Disponível em: <http://www.CIJ-cij.org/docket/index.php?p $1=3 \& \mathrm{p} 2=3 \& \mathrm{k}=64 \&$ case $=148 \& \operatorname{code}=\mathrm{aj} \& \mathrm{p} 3=4>$. Acesso em: 20 dez. 2014. p. 22. WATKINS, Casey. Whaling in the Antarctic: case analysis and suggestions for the future. New York International Law Review, v. 25, n. 2, p. 49-77, 2012. p. 62.

6 INTERNATIONAL COURT OF JUSTICE. 2014. 31 March. Whaling in the Antarctic Australia v. Japan: New Zealand intervening: mé- última hipótese seria aplicável caso a Austrália tivesse suscitado a proteção da biodiversidade e dos mamíferos marinhos em razão de seus direitos como detentor da ZEE, prevista em instrumentos como a Convenção das Nações Unidas para o Direito do Mar - UNCLOS ou Convenção de Montego Bay, ${ }^{7}$ porém fica claro que as violações alegadas pela parte demandante foram cuidadosamente selecionadas de modo a afastar a temática da planificação marinha de modo a manter a jurisdição da CIJ. ${ }^{8}$

Destaca-se também que não houve menção à jurisdição da Corte em relação às Convenções CBD e CITIES, que preveem expressamente outros meios de solução de controvérsias, como as negociações e a Corte Permanente de Arbitragem, antes de acionar a CIJ. ${ }^{9}$ Em verdade, é estranho o fato de sentença sequer cita esses instrumentos internacionais, suscitados pela Austrália em sua exordial.

Importante também observar a ausência de referência na sentença ao princípio da boa-fé, argumento muito utilizado pela Austrália e pela Nova Zelândia em suas alegações. Isso pode ter ocorrido de forma proposital, pois a boa-fé relaciona-se diretamente ao ônus da prova, de forma que, se a boa-fé do Japão fosse afirmada de modo expresso, caberia à Austrália, Estado autor da ação, o ônus da prova. Em contrapartida, se houvesse manifestação de que o Japão teria violado essa presunção, caberia a este comprovar fato extintivo das alegações realizadas pela Austrália. E ainda, caso a CIJ tivesse optado por utilizar essa via argumentativa, também teria que apreciar as alegações do Juiz ad hoc Charlesworth sobre a potencial inversão do ônus da prova à luz do princípio da precaução. ${ }^{10}$ De fato, os juízes Owada e

rits. Disponível em: <http://www.CIJ-cij.org/docket/index.php? $\mathrm{p} 1=3 \& \mathrm{p} 2=3 \& \mathrm{k}=64 \& \mathrm{case}=148 \& \mathrm{code}=\mathrm{aj} \& \mathrm{p} 3=4>$. Acesso em: 20 dez. 2014 p. 22.

7 UNITED NATIONS. Montego Bay Convention. Disponível em: $<$ http://www.un.org/Depts//los/convention_agreements/texts/ unclos/unclos_e.pdf>. Acesso em: 20 nov. 2014. art. 56, 61 e 65.

8 WATKINS, Casey. Whaling in the Antarctic: case analysis and suggestions for the future. New York International Law Review, v. 25, n. 2, p. 49-77, 2012. p. 62.

9 ANTON, Donald K. Dispute concerning Japan's JARPA II Program of 'Scientific Whaling' (Australia v. Japan): a backgrounder. ANU College of Law Research Paper, n. 33-10, 2010. Disponível em: $<$ http://ssrn.com/abstract=1632722>. Acesso em: 10 jan. 2015. p. $10-11$.

10 INTERNATIONAL COURT OF JUSTICE. 2014. 31 March. Whaling in the Antarctic Australia v. Japan: New Zealand intervening: opinion dissidente de M. le Juge Abraham. Disponível em: <http:// www.CIJ-cij.org/docket/files/148/18138.pdf>. Acesso em: 20 jan. 
Abraham mencionaram em seus votos divergentes que a presunção de boa-fé do Estado japonês foi violada, pois, apesar de a sentença não realizar menção expressa à boa-fé ou a ônus da prova, coube ao Japão dar "explicações, demonstrações e justificativas" quanto à Razoabilidade e cientificidade do projeto e não à Austrália provar que o projeto tinha finalidade diversa. ${ }^{11}$

Superadas essas questões, o Tribunal adentrou ao mérito do dissídio e analisou as razões apresentadas pela Austrália para solicitar a condenação do Japão e, consequentemente, a cassação da licença especial emitida para o JARPA II. Inicialmente, procedeu-se a uma retrospectiva sobre os primeiros documentos internacionais que regulamentaram a caça às baleias e seus respectivos contextos históricos. Nesse ínterim, restou demonstrado que, ao longo da primeira metade do século XX, diante da dependência econômica mundial de produtos provenientes das baleias (seu óleo era utilizado para acender lâmpadas, os ossos para fabricar espartilhos, a carne na alimentação) $)^{12}$ e da perspectiva de relação do homem com a natureza característica daquele período, as primeiras Convenções não tinham como finalidade a proteção do meio ambiente e da biodiversidade como um fim em si mesmo, ao contrário, tinham a mera finalidade de regular a caça e o comércio de baleias, mantendo a continuidade da exploração da atividade econômica e da elevação dos lucros.

Esse foi o contexto do nascedouro da Convenção Internacional para Regulação da Pesca a Baleias de 1946 que, em seu preâmbulo, afirma explicitamente ter por

2015. p. 07. WATKINS, Casey. Whaling in the Antarctic: case analysis and suggestions for the future. New York International Law Review, v. 25 , n. 2, p. 49-77, 2012. p. 63/64. FOSTER, Caroline. Motivations and methodologies: was Japan's whaling programme for purposes of scientific research? In: SIMPÓSIO WHALING IN THE ANTARCTIC: THE ICJ JUDGMENT AND ITS IMPLICATION, 2014, Kobe. Presentation Files and Papers... Kobe: Kobe University, 2014. Disponível em: <http://www.edu.kobe-u.ac.jp/ilaw/en/ whaling_docs/paper_Foster.pdf>. Acesso em: 10 jan. 2015.

11 INTERNATIONAL COURT OF JUSTICE. 2014. 31 March. Whaling in the Antarctic Australia v. Japan: New Zealand intervening: opinion dissidente de M. le Juge Abraham. Disponível em: <http:// www.CIJ-cij.org/docket/files/148/18138.pdf>. Acesso em: 20 jan. 2015. p. 07. INTERNATIONAL COURT OF JUSTICE. 2014. 31 March. Whaling in the Antarctic Australia v. Japan: New Zealand intervening: dissenting opinion of Judge Owada. Disponível em: <http:// www.CIJ-cij.org/docket/files/148/18138.pdf>. Acesso em: 20 dez. 2014. p. 14.

12 SANDS, Philippe. Principles of international environmental law. 2. ed. Cambridge: Cambridge University Press, 2003. p. 590-591. WATKINS, Casey. Whaling in the Antarctic: case analysis and suggestions for the future. New York International Law Review, v. 25, n. 2, p. 49-77, 2012. p. 52-53. objetivo promover a conservação dos estoques e, assim, possibilitar o desenvolvimento da indústria baleeira. ${ }^{13} \mathrm{~A}$ Convenção tem como parte integrante seu cronograma (schedule), que prevê sua atualização recorrente a fim de permitir que a proteção às baleias possa ocorrer de forma dinâmica, de acordo com o número de espécies existentes, estações do ano, desenvolvimento tecnológico etc. É permitido às partes se opor às alterações realizadas no cronograma, não se vinculando a elas, porém devem fazê-lo em até 90 (noventa) dias após a notificação das alterações. ${ }^{14}$

A Convenção criou uma Comissão Internacional sobre Caça às Baleias - IWC, composta por um membro de cada um dos países signatários, com competência para, entre outras, realizar alterações ao cronograma anexo à ICRW. A IWC também é composta por um secretariado, por um Comitê Financeiro e Administrativo, por um Comitê Científico, por um Comitê Técnico e outros Subcomitês $a d$ boc. ${ }^{15} \mathrm{O}$ Comitê Científico é composto por cientistas nomeados pelos Estados parte da Convenção e poderá receber o auxílio de organizações intergovernamentais e cientistas não nomeados pelos Estados, mas com notável saber em determinada área. Entre suas atribuições está a de analisar relatórios, que devem ser remetidos em periodicidade não superior a um ano, sobre as atividades desenvolvidas pelos países por meio de licenças especiais, e emitir avaliações não vinculantes sobre estes. ${ }^{16}$ Para o julgamento em análise, as atribuições e ações

13 Decidiu-se concluir uma convenção para promover a conservação dos estoques baleeiros e, assim, manter a possibilidade de desenvolvimento da indústria baleeira (tradução livre do original: "Having decided to conclude a convention to provide for the proper conservation of whale stocks and thus make possible the orderly development of the whaling industry" INTERNATIONAL WHALING COMMISSION. International Convention for the Regulation of Whaling, Washington, 2 December, 1946. Disponível em: <https://archive.iwc.int/pages/view. php? ref $=3607 \& \mathrm{k}=>$. Acesso em: 20 jan. 2015.

14 INTERNATIONAL WHALING COMMISSION. International Convention for the Regulation of Whaling, Washington, 2 December, 1946. Disponível em: <https://archive.iwc.int/pages/view. php? ref $=3607 \& k=>$. Acesso em: 20 jan. 2015; Preamble, art. V. ANTON, Donald K. Dispute concerning Japan's JARPA II Program of 'Scientific Whaling' (Australia v. Japan): a backgrounder. ANU College of Law Research Paper, n. 33-10, 2010. Disponível em: $<$ http://ssrn.com/abstract=1632722>. Acesso em: 10 jan. 2015. p. 02.

15 SANDS, Philippe. Principles of international environmental law. 2. ed. Cambridge: Cambridge University Press, 2003. p. 724.

16 INTERNATIONAL COURT OF JUSTICE. 2014. 31 March. Whaling in the Antarctic Australia v. Japan: New Zealand intervening: mérits. Disponível em: <http://www.CIJ-cij.org/docket/index.php?p $1=3 \& \mathrm{p} 2=3 \& \mathrm{k}=64 \&$ case $=148 \& \operatorname{code}=\mathrm{aj} \& \mathrm{p} 3=4>$. Acesso em: 20 dez. 2014. p. 27. 
da IWC e do Comitê Científico foram elementos cruciais, tanto para a tomada de decisão do Tribunal quanto para subsidiar as opiniões divergentes.

A partir da década de 1960, com a intensificação das ameaças de extinção a espécies de baleias e com o crescimento de um movimento dentro da IWC contrário a sua pesca, houve tentativa de mudança da perspectiva da Convenção, direcionando-a à proteção da biodiversidade marinha. Nesse contexto, o cronograma da ICRW foi alterado e previu em seu artigo 10(e) e 10(d) uma moratória à caça de baleias para fins comerciais, que teria início em 1986 e, inicialmente, seria revista na década de $1990 .{ }^{17}$ O Japão não tinha o propósito de aceitar essa moratória, no entanto, pressionado pelos Estados Unidos, foi obrigado a fazê-lo. ${ }^{18}$

Pouco tempo depois, a partir de 1987, o Japão iniciou o Projeto JARPA I que, com base em licença especial prevista no artigo VIII da ICRW, ${ }^{19}$ previa a necessidade da pesca de algumas espécies de baleias para fins de pesquisa científica, mais precisamente para calcular a o esto-

17 INTERNATIONAL WHALING COMMISSION. International Convention for the Regulation of Whaling, September 1946. Schedule, as amended by the Commission at the 64th Annual Meeting Panama City. Panama, July 2012. Disponível em: <https://archive. iwc.int $/$ pages $/$ view.php?ref=3606\&k=> . Acesso em: 20 jan. 2015 .. 18 ANTON, Donald K. Dispute concerning Japan's JARPA II Program of 'Scientific Whaling' (Australia v. Japan): a backgrounder. ANU College of Law Research Paper, n. 33-10, 2010. Disponível em: $<$ http://ssrn.com/abstract=1632722>. Acesso em: 10 jan. 2015. p. 04.

19 “Artigo VIII.1 Não obstante qualquer disposição contida na presente Convenção, qualquer Governo Contratante pode conceder a qualquer dos seus cidadãos uma licença especial, autorizando esse nacional a caçar, pescar e tratar baleias para fins de investigação científica, sujeitas a restrições quanto ao número e a outras condições que o Contratante Governo considere adequadas, e a caça, pesca e tratamento das baleias, de acordo com as provisões desse Artigo devem ser isentas da aplicação da presente Convenção. Cada Governo Contratante deve comunicar imediatamente à Comissão todas as licenças concedidas (tradução livre de: "Article VIII. 1. Notwithstanding anything contained in this Convention any Contracting Government may grant to any of its nationals a special permit authorizing that national to kill, take and treat whales for purposes of scientific research subject to such restrictions as to number and subject to such other conditions as the Contracting Government thinks fit, and the killing, taking, and treating of whales in accordance with the provisions of this Article shall be exempt from the operation of this Convention. Each Contracting Government shall report at once to the Commission all such authorizations which it has granted.'INTERNATIONAL WHALING COMMISSION. International Convention for the Regulation of Whaling, September 1946. Schedule, as amended by the Commission at the 64th Annual Meeting Panama City. Panama, July 2012. Disponível em: <https://archive.iwc.int $/$ pages/view.php?ref=3606\&k=>. Acesso em: 20 jan. 2015. que de baleias minke a fim de elidir algumas divergências relacionadas à moratória decretada. Apesar de as partes discordarem quanto à existência de reais contribuições desse projeto para a comunidade científica, a Corte pontuou que essa questão tinha natureza científica, logo não fazia parte da controvérsia jurídica em análise. ${ }^{20}$

No ano de 2005, com o fim do Projeto JARPA I, o Japão submeteu ao Comitê Científico um plano para a segunda fase de da pesquisa científica marinha sobre o ecossistema antártico e o manejo dos estoques de baleias, o Projeto JARPA II. Este tinha como objetivos principais: monitorar o ecossistema antártico, monitorar a competição entre espécies, analisar mudanças nos estoques ao longo do tempo e do espaço e melhorar o processo de manejo dos estoques de baleias na Antártida; para tal, previa a utilização de métodos letais e não letais a baleias do tipo minke, fin e jubarte.

Diante desses esclarecimentos, o primeiro aspecto do mérito analisado pela CIJ consistiu na interpretação que deve ser atribuída ao artigo VIII da ICRW. Isso porque, caso esse dispositivo fosse percebido como exceção à aplicação da Convenção, nenhuma das obrigações relativas à proteção ao meio ambiente e animais marinhos contidos na Convenção e em seu cronograma seriam vinculantes às pesquisas científicas concedidas sob licença especial, argumento defendido pelo Japão. Porém, caso fosse entendido como exceção restrita, as demais obrigações seriam aplicáveis, inclusive, às atividades de pesquisa científica sob licença especial, argumento defendido pela Austrália e pela Nova Zelândia. A esse respeito, a CIJ realizou interpretação conciliatória entre as duas posições, admitindo o artigo VIII como parte indissociável de um todo, portanto, devendo ser interpretada no contexto da Convenção, porém excepcionando a incidência das obrigações contidas nos artigos 10 (d) e $10\left(\right.$ e). ${ }^{21}$

A Convenção e seu Cronograma somente reconheceram a existência de três tipos de pesca às baleias: a que tem finalidade científica, a que tem finalidade comercial

20 INTERNATIONAL COURT OF JUSTICE. 2014. 31 March. Whaling in the Antarctic Australia v. Japan: New Zealand intervening: mérits. Disponível em: <http://www.CIJ-cij.org/docket/index.php?p $1=3 \& \mathrm{p} 2=3 \& \mathrm{k}=64 \&$ case $=148 \& \operatorname{code}=\mathrm{aj} \& \mathrm{p} 3=4>$. Acesso em: 20 dez. 2014. p. 40.

21 INTERNATIONAL COURT OF JUSTICE. 2014. 31 March. Whaling in the Antarctic Australia v. Japan: New Zealand intervening: mérits. Disponível em: <http://www.CIJ-cij.org/docket/index.php?p $1=3 \& \mathrm{p} 2=3 \& \mathrm{k}=64 \&$ case $=148 \& \operatorname{code}=\mathrm{aj} \& \mathrm{p} 3=4>$. Acesso em: 20 dez. 2014. p. 28-29. 
e a que visa à subsistência de grupos aborígenes. ${ }^{22} \mathrm{~A}$ esse respeito, o Tribunal acolheu as alegações da Austrália e da Nova Zelândia de que o artigo VIII seria aplicável somente às atividades de pesca unicamente destinadas a pesquisas científicas. Ressalte-se que o Juiz Antônio Augusto Cançado Trindade, que acompanhou o voto da maioria em relação a esse ponto, defendeu a aplicação do dispositivo da forma mais restrita possível para não desnaturar o propósito da Convenção e somente atividades com exclusiva destinação cientifica deveriam operar mediante licenças especiais, caso contrário o documento teria tido outra redação. ${ }^{23}$

Em contrapartida, em seu voto dissidente, o Juiz Abraham expôs que o simples fato do Japão considerar os ganhos para a indústria e o comércio baleeiro em suas atividades não seria o suficiente para desqualificar o JARPA II como um projeto de pesquisa científica. ${ }^{24}$ No mesmo sentido, o Juiz Bennounna juntou voto dissidente em que também entende ser possível que outras atividades sejam beneficiadas pela pesca de baleias ocorrida por meio de licença especial, no entanto, essas atividades devem estar relacionadas à pesquisa científica que ensejou a licença. ${ }^{25} \mathrm{~A}$ esse respeito, entende-se que essa constitui a posição mais acertada, pois, além de ser difícil distinguir a pesquisa científica da atividade comercial, conforme será melhor explicitado adiante por meio dos debates travados na Terceira Conferência das Nações Unidas sobre o Direito do Mar; o próprio texto da ICRW prevê em seu artigo VIII.2 que a carne proveniente das baleias pescadas deve ser tratada (podendo

22 INTERNATIONAL COURT OF JUSTICE. 2014. 31 March. Whaling in the Antarctic Australia v. Japan: New Zealand intervening: mérits. Disponível em: <http://www.CIJ-cij.org/docket/index.php ?p1 $=3 \& \mathrm{p} 2=3 \& \mathrm{k}=64 \&$ case $=148 \&$ code $=\mathrm{aj} \& \mathrm{p} 3=4>$. Acesso em: 20 dez. 2014. p. 30. INTERNATIONAL COURT OF JUSTICE. 2014. 31 March. Whaling in the Antarctic Australia v. Japan: New Zealand intervening: dissenting opinion of Judge Bennouna. Disponível em: $<$ http://www.CIJ-cij.org/docket/files/148/18144.pdf>. Acesso em: 20 jan. 2015. p. 05.

23 INTERNATIONAL COURT OF JUSTICE. 2014. 31 March. Whaling in the Antarctic Australia v. Japan: New Zealand intervening: separate opinion of judge Cançado Trindade. Disponível em: <http:/ / www.CIJ-cij.org/docket/files/148/18146.pdf>. Acesso em: 20 jan. 2015. p. 07.

24 INTERNATIONAL COURT OF JUSTICE. 2014. 31 March. Whaling in the Antarctic Australia v. Japan: New Zealand intervening: opinion dissidente de M. le Juge Abraham. Disponível em: < http://www.CIJcij.org/docket/files/148/18138.pdf>. Acesso em: 20 jan. 2015. p. 06. 25 INTERNATIONAL COURT OF JUSTICE. 2014. 31 March. Whaling in the Antarctic Australia v. Japan: New Zealand intervening: dissenting opinion of judge Bennouna. Disponível em: <http://www.CIJ-cij. org/docket/files/148/18144.pdf >. Acesso em: 20 jan. 2015. p. 02. ser vendida) e seus proventos serão utilizados conforme determinação do governo concessor da licença - no caso do Japão, é utilizada para subsidiar as pesquisas do Instituto para Pesquisa de Cetáceos (Institute of Cetacean Research - ICR) ${ }^{26}{ }^{27} \operatorname{logo}$, a própria Convenção possibilita a utilização dos produtos da pesca para fins diversos da investigação científica. A Corte chegou a inclinar-se a essa concepção quando, no ponto 97 do acórdão, mencionou que o fato de alguns nacionais terem motivações que vão além da pesquisa científica não desnatura a finalidade científica de determinada pesquisa, porém o fez de forma muito comedida ao ter se referido somente a indivíduos (officials). ${ }^{28}$

As considerações realizadas até este ponto contextualizaram a lide apreciada pela Corte. Apresentou-se a controvérsia em questão, o problema jurídico posto a ser decidido, o momento histórico de criação da principal convenção internacional suscitada (ICRW) e sua mudança de perspectiva, a construção dos Projetos JARPA I e JARPA II, as modalidades de pesca previstas convencionalmente e o entendimento firmado em relação à aplicação do artigo VIII da Convenção. No próximo tópico, analisar-se-á a metodologia utilizada pela corte para apreciar se a pesca de baleias realizada no âmbito do Projeto JARPA II está contida no quadro normativo do artigo VIII da ICRW e como a definição de pesquisa científica marinha foi abordada pelo Tribunal.

\section{O CRITÉRIO DE EXAME DA LICENÇA ESPECIAL E A (NÃO) DEFINIÇÃO DE PESQUISA CIENTÍFICA MARINHA}

O caso em comento tem como pano de fundo a política japonesa de condução de pesquisas científicas,

26 A Corte avalia essa disposição no ponto 94, afirmando que a simples venda da carne não descaracteriza a finalidade científica de uma pesquisa, afirmação que gera ambiguidades caso comparada com as considerações iniciais do julgamento.

27 WATKINS, Casey. Whaling in the Antarctic: case analysis and suggestions for the future. New York International Law Review, v. 25, n. 2, p. 49-77, 2012. p. 20; ARON, William; BURKE, William; FREEMAN, Milton. Scientists versus whaling: science, advocacy, and errors of judgment. Bioscience, v. 52, n. 12, p. 1137-1140, 2002. p. 1139. 28 INTERNATIONAL COURT OF JUSTICE. 2014. 31 March. Whaling in the Antarctic Australia v. Japan: New Zealand intervening: mérits. Disponível em: <http://www.CIJ-cij.org/docket/index.php?p $1=3 \& \mathrm{p} 2=3 \& \mathrm{k}=64 \&$ case $=148 \& \operatorname{code}=a j \& \mathrm{p} 3=4>$. Acesso em: 20 dez. 2014. p. 38. 
questão que foge do âmbito puramente jurídico. A esse respeito, as partes concordaram que determinar se a captura, a pesca e o tratamento de baleias mediante licença especial é para fins científicos não constitui uma discricionariedade ilimitada dos Estados. Então, a CIJ teve que construir uma forma de analisar se a captura, a pesca e o tratamento de baleias, realizados no Projeto JARPA II tinham finalidade científica, à luz do disposto no artigo VIII da ICRW.

Para realizar esse intento, sem adentrar no mérito científico, a CIJ utilizou, pela primeira vez, a metodologia do standard of review ou "critério de exame" da licença especial expedida pelo Japão ao JARPA II. Essa metodologia, já havia sido utilizada pelo Órgão de Apelação da Organização Mundial do Comércio - OMC para analisar seu Acordo sobre Medidas Sanitárias e Fitossanitárias nos casos Canada-Continued Suspension of Obligations in the EC-Hormones Dispute; US-Continued Suspension of Obligations in the EC-Hormones Dispute e Australia: Measures Affecting the Importation of Apples from New Zealand, e em que argumentos atinentes à comunidade científica também tiveram um papel central na resolução da disputa. ${ }^{29} \mathrm{Tem}$-se, portanto, um interessante caso em que a CIJ expandiu o seu regime de funcionamento e demonstrou abertura para a jurisprudência de outros tribunais e, inclusive, incorporou ferramentas utilizadas por outrem. ${ }^{30}$

29 FOSTER, Caroline. Motivations and methodologies: was Japan's Whaling programme for purposes of scientific research? In: SIMPÓSIO WHALING IN THE ANTARCTIC: THE ICJ JUDGMENT AND ITS IMPLICATION, 2014, Kobe. Presentation Files and Papers... Kobe: Kobe University, 2014. Disponível em: <http:/ / www.edu.kobe-u.ac.jp/ilaw/en/whaling_docs/paper_Foster.pdf $>$. Acesso em: 10 jan. 2015.

30 No mesmo sentido, posiciona-se FOSTER: "É notável que a Corte tenha empregado a terminologia critério de revisão como se já fosse uma técnica estabelecida na Corte. Talvez isso seja uma evidencia de que a Corte se considera como pertencente a um grupo coletivo de cortes e tribunais, em que a ideia de critério de revisão tornou-se conhecida no direito internacional, particularmente por meio das disputas comerciais, e decorrente das concepções préRodada do Uruguai de que os processos que deveriam ser desenvolvidos para a resolução das disputas comerciais multilaterais na Organização Mundial do Comércio deveriam ser vistas como uma forma de revisão e não como julgamento" (tradução livre do original: "It is notable that the Court employed the terminology of standard of review as though it were already an established technique for the Court. This is perbaps evidence that the Court considers itself as belonging to a collective group of international courts and tribunals, within which the idea of standard of review has become known to international law, particularly through trade disputes, and stemming primarily from pre-Uruguay Round conceptions that the processes to be developed for the settlement of multilateral trade disputes in the World Trade Organization should be seen as a form of review rather than ad-
Interessante notar, na esteira do que é afirmado por Foster, que, em nenhum momento na sentença, a CIJ menciona que se utilizará de uma ferramenta metodológica construída e aplicada majoritariamente no âmbito da OMC. Somente no voto dissidente do Juiz Owada é retomada a discussão sobre os limites entre a ciência e o direito enfrentados pelo Órgão de Apelação da OMC no caso Continued Suspension of Obligations in the EC-Hormones e sobre a amplitude de revisão do órgão, defende que o Estado concessor da licença tem presunção de boa-fé e que a competência de análise das bases científica e tecnológicas de determinada licença especial é da Comissão Internacional sobre Caça às Baleias, mais especificamente do Comitê Científico, de modo que somente caberia à CIJ analisar se a expedição da licença cumpre os requisitos elencados no artigo VIII e se possui motivações coerentes e forte embasamento científico. ${ }^{31}$ De forma análoga, o Juiz Yusuf acrescentou que o IWC revisou a licença concedida ao Projeto JARPA II em 2005 e não se posicionou contrário à pesquisa, enquanto o fez em oportunidades anteriores em relação a outras licenças, quando achou que não haveria enquadramento como investigação científica. ${ }^{32}$

O critério de exame é baseado, sobretudo, na ideia de deferência, ou seja, na obediência que o tribunal superior terá em relação à decisão do tribunal que proferiu a decisão e, consequentemente, à margem de apreciação para anular ou reformular a decisão do tribunal inferior. Assim, quando há baixo grau de deferência, o tribunal superior poderá anular a decisão de forma fácil, em contrapartida, quando existe alto grau de defe-

judication" (FOSTER, Caroline. Motivations and methodologies: was Japan's Whaling programme for purposes of scientific research? In: SIMPÓSIO WHALING IN THE ANTARCTIC: THE ICJ JUDGMENT AND ITS IMPLICATION, 2014, Kobe. Presentation Files and Papers... Kobe: Kobe University, 2014. Disponível em: <http:/ / www.edu.kobe-u.ac.jp/ilaw/en/whaling_docs/paper_Foster.pdf $>$. Acesso em: 10 jan. 2015). Em sentido semelhante ver: MATZLÜCK, Nele. Norm interpretation across international regimes: competences and legitimacy. In: YOUNG, Margaret (Org.). Regime interaction in international law: facing fragmentation. Cambridge: Cambridge University Press, 2012. p. 201-234.

31 INTERNATIONAL COURT OF JUSTICE. 2014. 31 March. Whaling in the Antarctic Australia v. Japan: New Zealand intervening: dissenting opinion of judge Owada. Disponível em: <http://www.CIJcij.org/docket/files/148/18138.pdf>. Acesso em: 20 dez. 2014. p. 13.

32 INTERNATIONAL COURT OF JUSTICE. 2014. 31 March. Whaling in the Antarctic Australia v. Japan: New Zealand intervening: dissenting opinion of judge Yusuf. Disponível em: < http://www.CIJcij.org/docket/files/148/18148.pdf>. Acesso em: 20 dez. 2014. p. 09. 
rência, a decisão somente poderá ser anulada caso seja evidenciado um erro contundente. Essa metodologia é particularmente familiar ao direito comunitário europeu e ao direito estadunidense, que tem sido fomentado o uso dessa ferramenta em âmbito da OMC. Situação peculiar ocorre quando essa metodologia é transmutada para o plano internacional, pois então oportuniza-se aos tribunais internacionais apreciar questões ligadas à política estatal, notadamente em setores estratégicos como: saúde, meio ambiente, biossegurança. Assim, abre-se uma janela de possibilidades aos tribunais para o desenvolvimento de práticas não fundamentadas no consentimento soberano estatal ou no entendimento das competências do órgão de solução de controvérsias no direito internacional público, o que pode gerar decisões arbitrárias, inconsistentes ou mesmo ocasionar afastamento dos Estados do meio de solução de controvérsias. Ademais, essa ferramenta trabalha com a terminologia "revisão" e não "julgamento", fato que já sinaliza para a melhor adequação dessa ferramenta a meios de solução de controvérsia não jurisdicionais ou à arbitragem. ${ }^{33}$

Transmutando esse entendimento para o caso em comento, a aplicação dessa metodologia permitiu à CIJ ir além do julgamento sobre o preenchimento dos requisitos procedimentais para o enquadramento na exceção prevista no artigo VIII ou mesmo da existência de vício, e revisar o mérito científico da licença concedida para a pesquisa científica marinha japonesa.

Nesse contexto, a Corte não seguiu estritamente nenhum dos critérios propostos pelas partes e, no parágrafo 67 da sentença, complementado pelo parágrafo 88, elencou os critérios de exame desenvolvidos para nortear a análise da licença especial concedida. Pela centralidade que esses trechos possuem na crítica empreendida neste estudo, é interessante citá-los:

67. Ao analisar a concessão de uma licença especial autorizando a captura, a pesca e o tratamento de baleias, o Tribunal irá avaliar, primeiramente, [] se o programa em que ocorrem essas atividades envolve pesquisa científica. Em segundo lugar, [II] o Tribunal irá considerar se a captura, a pesca e o tratamento de baleias é "para fins de" pesquisa científica examinando

33 FOSTER, Caroline. International Adjudication - standard of review and burden of proof: Australia-Apples and whaling in the Antarctic. Review of European Community and International Environmental Law, v. 21, n. 2, p. 80-91, 2012. Disponível em: < http://www. law.auckland.ac.nz/people/c-foster>. Acesso em: 10 jun. 2015. p. 80-85. se a concepção $0^{34}$, a implementação e os resultados obtidos pela pesquisa são razoáveis em relação à consecução dos seus objetivos declarados. Este tipo de critério de exame é objetivo. Elementos relevantes da concepção e da implementação de um programa são apresentados abaixo (ver parágrafo 88).

$[\ldots]$

88. Os objetivos declarados de um programa de pesquisa são a base de sua concepção, mas a Corte não precisa julgar o mérito científico ou a importância desses para avaliar a finalidade da caça às baleias no âmbito de um programa. Também não é atribuição da Corte decidir se a concepção e a implementação de um programa são os melhores meios possíveis para atingir os seus objetivos declarados.

Para verificar se o uso de métodos letais em um programa é para fins de investigação científica, o Tribunal irá considerar se os elementos da concepção e da implementação de um programa são razoáveis em relação aos seus objetivos científicos declarados (ver parágrafo 67 acima). Como mostrado pelos argumentos das partes, tais elementos podem incluir: [II.a] as decisões relativas à utilização de métodos letais; [II.b] a escala de utilização de amostras letais pelo programa; [II.c] a metodologia utilizada para selecionar a quantidade das amostras; [II.d] uma comparação da quantidade de amostras previstas e a quantidade efetivamente capturada; [II.e] o período de tempo de um programa; [II.f] produção científica gerada pelo programa; e [II.g] do grau em que um programa coordena suas atividades com projetos de pesquisa relacionados. ${ }^{35}$

34 Concepção é utilizada neste artigo como sinônimo ao termo "design" no original em inglês e "conception" no original em francês.

35 Tradução livre do original: "67. When reviewing the grant of a special permit authorizing the killing, taking and treating of whales, the Court will assess, first, whether the programme under which these activities occur involves scientific research. Secondly, the Court will consider if the killing, taking and treating of whales is 'for purposes of' scientific research by examining whether, in the use of lethal methods, the programme's design and implementation are reasonable in relation to achieving its stated objectives. This standard of review is an objective one. Relevant elements of a programme's design and implementation are set forth below (see paragraph 88$)$. [...] 88. The stated research objectives of a programme are the foundation of a programme's design, but the Court need not pass judgment on the scientific merit or importance of those objectives in order to assess the purpose of the killing of whales under such a programme. Nor is it for the Court to decide whether the design and implementation of a programme are the best possible means of achieving its stated objectives. In order to ascertain whether a programme's use of lethal methods is for purposes of scientific research, the Court will consider whether the elements of a programme's design and implementation are reasonable in relation to its stated scientific objectives (see paragraph 67 above). As shown by the arguments of the Parties, such elements may include: decisions regarding the use of lethal methods; the scale of the programme's 
Em relação ao primeiro item ([i] se o programa em que ocorrem essas atividades envolve pesquisa científica), a importância da pesquisa científica marinha para o desenvolvimento do direito do mar é inquestionável, seja para a proteção do ecossistema marinho e seu manejo em conformidade com o principio da precaução, seja para o descobrimento das potencialidades presentes nos fundos marinhos e na camada de água acima deles. ${ }^{36}$ Ocorre que, apesar do amplo reconhecimento dos benefícios que essa atividade proporciona para a humanidade, a ICRW não prevê definição sobre pesquisa científica, tampouco se conhece instrumento internacional que pudesse dar suporte à Corte com relação a esse termo. Em verdade, o conceito de pesquisa científica marinha chegou a ser discutido na Segunda e Terceira Conferências das Nações Unidas sobre o Direito do Mar e num estudo sobre a relação entre a Convenção das Nações Unidas sobre Direito do Mar e a Convenção sobre Biodiversidade, existindo algumas propostas. ${ }^{37}$ No entanto, não houve consenso sobre a

use of lethal sampling; the methodology used to select sample sizes; a comparison of the target sample sizes and the actual take; the time frame associated with a programme; the programme's scientific output; and the degree to which a programme co-ordinates its activities with related research projects (see paragraphs 129-132; 149; 158-159; 203-205; 214-222 below)" INTERNATIONAL COURT OF JUSTICE. 2014. 31 March. Whaling in the Antarctic Australia v. Japan: New Zealand intervening: mérits. Disponível em: <http://www. CIJ-cij.org $/$ docket $/$ index.php?p1 $=3 \& p 2=3 \& \mathrm{k}=64 \&$ case $=148 \&$ co de $=$ aj\&p $3=4>$. Acesso em: 20 dez. 2014. p. 32 e 36.

36 TANAKA, Yoshifumi. The international law of the sea. Cambridge: Cambridge University Press, 2012. p. 335-338. UNITED NATIONS. Division for Ocean Affairs and the Law of the Sea Office of Legal Affairs. Marine scientific research: a revised guide to the implementation of the relevant provisions of the United Nations Convention on the Law of the Sea. New York, 2010. p. 04-06.

37 "Na ausência de uma definição formal, pesquisa científica marinha poderia ser definida como uma atividade que envolve a coleta e a análise de informações, dados ou amostras, objetivando expandir o conhecimento da humanidade sobre o meio ambiente, e não é realizada com intento de ganho econômico. Como o objetivo consiste no desenvolvimento do conhecimento, a pesquisa cientifica marinha é caracterizada pela abertura, disseminação de dados, troca de amostras, assim como pela publicação e disseminação dos resultados das pesquisas, como previsto na Parte XIII" (tradução livre do original: "47. In the absence of a formal definition, marine scientific research could be defined as an activity that involves collection and analysis of information, data or samples aimed at increasing mankind's knowledge of the environment, and is not undertaken with the intent of economic gain. Since the object is the enhancement of knowledge, marine scientific research is characterized by openness, dissemination of data, exchange of samples, as well as publication and dissemination of research results as provided for in Part XIII" United Nations Environment Programme. Study of the relationship between the Convention on Biological Diversity and the United Nations Convention on the Law of the Sea with regard to the conservation and sustainable use of genetic resources on the deep seabed (decision II/10 of the Conference of the Parties to possibilidade de realizar uma distinção clara entre a pesquisa científica pura e a exploração - que se trata de pesquisa científica, visando identificar potencialidades comerciais. Como classificar, por exemplo, uma pesquisa realizada em Universidade que, após chegar a resultados positivos dá ensejo a novo mecanismo tecnológico que começa a ser vendido no mercado, mesmo que em pequena escala?

Embora alguns doutrinadores, como Tanaka, proponham formas de diferenciar as duas atividades, como saber se a pesquisa tem pretensões de ser publicada, haja vista que pesquisas que visam à explotação tendem a ser secretas, ${ }^{38}$ a comunidade internacional optou por não criar um conceito preciso de pesquisa científica marinha, muito embora existam tratados que contém princípios que devem nortear essa atividade, quais sejam, a) ser realizada exclusivamente com fins pacíficos; (b) ser realizada com métodos e meios científicos adequados e compatíveis com a Convenção; (c) não interferir injustificadamente com outras utilizações legítimas do mar compatíveis com a Convenção; e (d) ser realizada em conformidade com todas as normas relevantes adotadas no contexto da Convenção, incluindo as relacionadas à proteção e preservação do ambiente marinho. ${ }^{39}$ Apesar de esses princípios estarem previstos no art. 240 da Convenção das Nações Unidas para o Direito do Mar UNCLOS, tratado não invocado pelas partes, entende-se que não haveria óbice alguma em utilizá-los como ferramenta para nortear a análise do Projeto JARPA II, tendo em vista que a CIJ utilizou no mesmo julgamento um ferramental metodológico da OMC.

A esse respeito, ao analisar o grau de abertura de um tratado para considerar normas extrínsecas no processo de interpretação Mazt-Lück utiliza-se das quatro possibilidades de leitura do artigo 31(3)(c) da Convenção de Viena sobre Direito dos Tratados propostas por McLachlan, quais sejam: (1) todas as partes do tratado interpretado também devem ser parte do tratado extrínseco; (2) ao menos as partes em disputa judicial devem ser

the Convention on Biological Diversity). Disponível em: <https://www. cbd.int/doc/meetings/sbstta/sbstta-08/information/sbstta-08-inf03-rev1-en.doc >. Acesso em: 24 out. 2014.

38 TANAKA, Yoshifumi. The international law of the sea. Cambridge: Cambridge University Press, 2012. p. 335-338.

39 UNITED NATIONS. Division for Ocean Affairs and the Law of the Sea Office of Legal Affairs. Marine scientific research: a revised guide to the implementation of the relevant provisions of the United Nations Convention on the Law of the Sea. New York, 2010. p. 04-06. 
partes do tratado invocado no processo interpretativo; (3) se há disparidade das partes dos tratados, a regra do tratado em questão deve ter o status de costume international para ser aplicada; e (4) quando não há identidade completa entre as partes, a norma extrínseca deve ser implicitamente aceita ou tolerada. ${ }^{40}$ No caso em análise, os dois países - três a Nova Zelândia também for considerada — são partes das duas Convenções, logo, a primeira hipótese seria aplicável, portanto, perfeitamente possível a utilização do norte proporcionado pela UNCLOS.

Um expert, indicado pela Austrália propôs quatro critérios caracterizadores de uma pesquisa cientifica: a) objetivos definidos e alcançáveis que se propõem a contribuir com a conservação e o gerenciamento dos estoques; b) métodos apropriados, inclusive utilizando métodos letais, somente na ausência de outros; c) revisão por pares; e d) não causar efeitos adversos aos estoques. Contudo, essa proposta não foi aceita pela Corte, que também não considerou necessário aplicar nenhum princípio, identificar critérios alternativos ou propor definição geral de pesquisa científica. ${ }^{41}$ Mesmo assim, surpreendentemente, nos pontos 127 e 172 do acórdão, ela afirma que as atividades do JARPA II podem ser, genericamente, caracterizadas como pesquisa científica e no ponto 230 afirma não ser necessário identificar se o projeto tem fins comerciais. ${ }^{42}$

Em razão da importância desses argumentos para a presente crítica, cumpre transcrever os trechos da sentença:

86. Levando em consideração essas observações, a Corte não concorda que as atividades devam satisfazer os quatros critérios propostos pela Austrália para constituírem uma "pesquisa científica" no contexto do artigo VIII. Tais como foram formulados pela Austrália, esses critérios parecem refletir mais o que um dos experts invocados chamou

40 MATZ-LÜCK, Nele. Norm interpretation across international regimes: competences and legitimacy. In: YOUNG, Margaret (Org.). Regime interaction in international law: facing fragmentation. Cambridge: Cambridge University Press, 2012. p. 201-234. p. 213.

41 INTERNATIONAL COURT OF JUSTICE. 2014. 31 March. Whaling in the Antarctic Australia v. Japan: New Zealand intervening: mérits. Disponível em: <http://www.CIJ-cij.org/docket/index.php?p $1=3 \& \mathrm{p} 2=3 \& \mathrm{k}=64 \&$ case $=148 \& \operatorname{code}=\mathrm{aj} \& \mathrm{p} 3=4>$. Acesso em: 20 dez. 2014. p. 33.

42 INTERNATIONAL COURT OF JUSTICE. 2014. 31 March. Whaling in the Antarctic Australia v. Japan: New Zealand intervening: mérits. Disponível em: <http://www.CIJ-cij.org/docket/index.php?p $1=3 \& \mathrm{p} 2=3 \& \mathrm{k}=64 \&$ case $=148 \& \operatorname{code}=\mathrm{aj} \& \mathrm{p} 3=4>$. Acesso em: 20 dez. 2014. p. 44. de pesquisa científica propriamente dita do que uma forma de interpretar o termo tal qual utilizado na Convenção. A Corte não considera necessário apresentar critérios alternativos ou oferecer uma definição geral de "pesquisa científica".

127. [...] Baseado nas informações apresentadas, a Corte entende que as atividades do JARPA II envolvendo as amostras letais de baleias podem ser genericamente caracterizadas como "pesquisa científica". Não é necessário, dessa forma, no contexto do caso, examinar genericamente o conceito de "pesquisa científica" [...]

172. Ao considerar essas alegações das Partes, a Corte reitera que não pretende aqui julgar o mérito científico dos objetivos do JARPA II e que as atividades do JARPA II podem ser genericamente caracterizadas como "pesquisa científica" $[. ..] .{ }^{43}$

Ora, visando esquivar-se da análise de mérito científico, a CIJ construiu uma metodologia de exame (ou reexame) focada na finalidade do Projeto JARPA II ou, em outras palavras, na razoabilidade da decisão estatal em conceder a licença especial para o projeto. Tal estratégia originou divisão entre "pesquisa científica" e "pesquisa para fins científicos" artificial e confusa, que dá ensejo a situações absurdas como atividade que, apesar de configurar-se como pesquisa científica, não possui finalidade científica ou não teve sua licença especial concedida com finalidade científica. ${ }^{44}$ Ademais, segun-

43 Tradução livre dos seguintes trechos: "86. Taking into account these observations, the Court is not persuaded that activities must satisfy the four criteria advanced by Australia in order to constitute 'scientific research' in the context of Article VIII. As formulated by Australia, these criteria appear largely to reflect what one of the experts that it called regards as well-conceived scientific research, rather than serving as an interpretation of the term as used in the Convention. Nor does the Court consider it necessary to devise alternative criteria or to offer a general definition of 'scientific research'. 127. [...] Based on the information before it, the Court thus finds that the JARPA II activities involving the lethal sampling of whales can broadly be characterized as 'scientific research'. There is no need therefore, in the context of this case, to examine generally the concept of 'scientific research' [...]. 172. In considering these contentions by the Parties, the Court reiterates that it does not seek here to pass judgment on the scientific merit of the JARPA II objectives and that the activities of JARPA II can broadly be characterized as 'scientific research' [...]"INTERNATIONAL COURT OF JUSTICE. 2014. 31 March. Whaling in the Antarctic Australia v. Japan: New Zealand intervening: mérits. Disponível em: <http:/ $/$ www.CIJ-cij.org/docket/index.php?p1=3\&p2=3\&k= $64 \&$ case $=148 \&$ code $=$ aj\&p3 $=4>$. Acesso em: 20 dez. 2014. p. 35$36 ; 44-45 ; 54$.

44 INTERNATIONAL COURT OF JUSTICE. 2014. 31 March. Whaling in the Antartic Australia v. Japan: New Zealand intervening: dissenting opinion of judge Bennouna. Disponível em: <http://www. CIJ-cij.org/docket/files/148/18144.pdf >. Acesso em: 20 jan. 2015. p. 03. INTERNATIONAL COURT OF JUSTICE. 2014. 31 March. Whaling in the Antartic Australia v. Japan: New Zealand interven- 
do apontado pelos Juízes Owada e Yusuf, os critérios utilizados pela CIJ para identificar a razoabilidade do projeto são externos à Convenção, principal base normativa para a análise jurídica da Corte, além de serem subjetivos. Avaliar a concepção e implementação foge do campo jurídico de atuação e se inserem em atividade de cunho técnico-científico, de competência da Comissão Internacional sobre Caça às Baleias, em última instância de seu Comitê Cientifico. ${ }^{45}{ }^{4}{ }^{46}$

Nessa linha de raciocínio, Sakai complementa que:

tal metodologia adotada pela Corte também parece ser estranha. [...] O importante nesse caso é se as atividades do JARPA II envolvem pesquisa, sob respaldo do artigo VIII da ICRW. O teste para saber se a decisão estatal é objetivamente razoável, como arguido pelo Japão, deveria ter considerado como critério de exame o termo 'pesquisa para fins científicos' como um todo, e não dissociar o termo 'para fins de'. Terceiro, quando a Corte estabelece que o Japão cumpriu com suas obrigações previstas no parágrafo 30 do cronograma da ICRW, não poderia ser dito que as atividades do JARPA II foram reconhecidas como 'pesquisa científica'? Se 'a pesca científica de baleias, mesmo com falhas, continua a ser científica em sua natureza', as atividades do JARPA II continuam a ser 'pesquisa científica' ilegal? ${ }^{47}$

ing: dissenting opinion of judge Yusuf. Disponível em: $<$ http:// www.CIJ-cij.org/docket/files/148/18148.pdf>. Acesso em: 20 dez. 2014. p. 14.

45 O Juiz Yusuf acrescenta que na única oportunidade em que um padrão de avaliação baseado na razoabilidade foi utilizado foi no Caso Elettronica Sicula, mas, nessa oportunidade, o critério surgiu da Convenção e não de uma criação própria da Corte. (INTERNATIONAL COURT OF JUSTICE. 2014. 31 March. Whaling in the Antarctic Australia v. Japan: New Zealand intervening: dissenting opinion of judge Yusuf. Disponível em: <http://www.CIJ-cij.org/docket/ files/148/18148.pdf > . Acesso em: 20 dez. 2014. p. 03-04).

46 INTERNATIONAL COURT OF JUSTICE. 2014. 31 March. Whaling in the Antarctic Australia v. Japan: New Zealand intervening: dissenting opinion of judge Owada. Disponível em: <http://www.CIJcij.org/docket/files/148/18138.pdf>. Acesso em: 20 dez. 2014, p. 08.

47 Tradução livre do seguinte trecho: "Such methodology adopted by the Court also appears to be strange. [...]The matter in this case is whether the JARPA II activities would involve scientific research under Article VIII of the ICRW. The test of whether a State's decision is objectively reasonable, which Japan argues, should have been considered as a standard of review of 'for purpose of science research' as a whole, not of 'for purposes of' separately. Third, when the Court finds that Japan has complied with its obligations under paragraph 30 of the Schedule to the ICRW, may it be said that the JARPA II activities have been recognized as 'scientific research' by the Court? If 'scientific whaling, even if with flaws, remains scientific in nature' is the JARPA II activities still illegal 'science research'?" SAKAI, Hironobu. After the whaling case: its lessons from a japanese perspective. In: WHALING IN THE ANTARCTIC: THE ICJ JUDGMENT AND ITS IMPLICATION, 2014, Kyoto. Paper...
Em seguida, tendo sido acordado entre as partes que os pontos I e II são cumulativos, ${ }^{48}$ a Corte analisou se a captura, a pesca e o tratamento de baleias realizado pelo JARPA II foram desenvolvidos "para fins de" pesquisa científica. A concepção do projeto foi avaliada por meio de quatro elementos presentes no Plano de Pesquisa: a) objetivos; b) período e área de pesquisa; c) métodos utilizados e quantidade das amostras; d) possíveis repercussões das atividades nos estoques de baleias existentes. ${ }^{49}$ É interessante observar também que os elementos que configuram a concepção (ou design) do projeto são semelhantes àqueles apresentados pelo expert convocado pela Austrália, ou seja, embora os critérios elencados por ele não tenham sido considerados para a definição de pesquisa científica, parecem ter guiado a investigação das finalidades do JARPA II, muito embora a Corte não tenha feito menção explícita a isso. ${ }^{50}$

Desses elementos, o Tribunal deu ênfase aos métodos utilizados e à quantidade de amostras, mais especificamente ao uso de métodos letais e ao incremento da quantidade de amostras previstas no JARPA II em relação ao JARPA I. Sobre o uso de métodos letais, observou-se a parca fundamentação no Plano de Pesquisa e no processo para continuar utilizando-os no JARPA II, mesmo após o incremento tecnológico que permitiu outras formas de obtenção de dados em comparação ao período em que foi implantado o JARPA I. Segundo opinião da maioria dos juízes, o fato de optar pelo uso de métodos letais sem dados consistentes que demonstrem não ser possível obter os resultados propostos por métodos não letais levantou dúvidas sobre a finalidade científica da pesquisa. ${ }^{51} \mathrm{Na}$ análise da implementação do

Kyoto: Kyoto University, 2014. Disponível em: <http://www.edu. kobe-u.ac.jp/ilaw/en/whaling_docs/paper_Sakai.pdf $>$. Acesso em: 20 jan. 2015.

48 INTERNATIONAL COURT OF JUSTICE. 2014. 31 March. Whaling in the Antarctic Australia v. Japan: New Zealand intervening: mérits. Disponível em: <http://www.CIJ-cij.org/docket/index.php?p $1=3 \& \mathrm{p} 2=3 \& \mathrm{k}=64 \&$ case $=148 \& \operatorname{code}=\mathrm{aj} \& \mathrm{p} 3=4>$. Acesso em: 20 dez. 2014. p. 32.

49 INTERNATIONAL COURT OF JUSTICE. 2014. 31 March. Whaling in the Antarctic Australia v. Japan: New Zealand intervening: mérits. Disponível em: <http://www.CIJ-cij.org/docket/index.php?p $1=3 \& \mathrm{p} 2=3 \& \mathrm{k}=64 \&$ case $=148 \& \operatorname{code}=\mathrm{aj} \& \mathrm{p} 3=4>$. Acesso em: 20 dez. 2014. p. 41-44.

50 INTERNATIONAL COURT OF JUSTICE. 2014. 31 March. Whaling in the Antarctic Australia v. Japan: New Zealand intervening: dissenting opinion of judge Owada. Disponível em: <http:/ / www.CIJcij.org/docket/files/148/18138.pdf>. Acesso em: 20 dez. 2014.p. 10.

51 INTERNATIONAL COURT OF JUSTICE. 2014. 31 March. Whaling in the Antarctic Australia v. Japan: New Zealand intervening: mé- 
projeto, a Corte observou que o número de baleias pescadas até aquele momento foi inferior ao inicialmente previsto, fato que aumentou a insegurança quanto aos números apresentados na concepção do JARPA II..$^{52}$

A Corte analisou também os demais elementos identificados no parágrafo 88 como: a) tempo de duração da pesquisa; b) resultados científicos do JARPA II até aquele momento; e c) cooperação com outras instituições de pesquisa. Em relação a eles, que foram abordados de forma superficial, aquele que mais chama atenção é a alegada pouca produção acadêmica revisada por pares - novamente, o critério formulado pelo expert da Austrália foi seguido. Segundo os representantes japoneses, apesar de terem sido produzidos somente 2 artigos revisados por pares, houve também 3 apresentações em simpósios e 8 artigos apresentados ao IWC. ${ }^{53} \mathrm{~A}$ esse respeito, necessário fazer remissão às alegações realizadas pelo Juiz Owada em seu voto no qual ele rememora o pronunciamento feito pelo Presidente da IWC em 2007 sobre a relevância científica dos Projetos JARPA e JARPA II e a revisão do projeto JARPA II que seria realizada no mesmo ano do julgamento (2014), logo, não seria o caso da Corte realizar análise antecipada sobre o caráter técnico-científico do projeto, já que a entidade responsável para tal fá-lo-ia em período próximo. ${ }^{54}$

Em relação às informações produzidas pelo Japão a cada um dos sete elementos elencados no parágrafo 88, Corte Internacional de Justiça entendeu que elas foram insuficientes, duvidosas e inadequadas à concepção e implementação do projeto de pesquisa científica, desta feita julgou que o projeto JARPA II não teve finalidade científica, apesar de ter expressamente concebido essa pesquisa como científica e ter rechaçado seu enquadra-

rits. Disponível em: <http://www.CIJ-cij.org/docket/index.php? $\mathrm{p} 1=3 \& \mathrm{p} 2=3 \& \mathrm{k}=64 \& \mathrm{case}=148 \&$ code $=\mathrm{aj} \& \mathrm{p} 3=4>$. Acesso em: 20 dez. 2014. p. 40-61.

52 INTERNATIONAL COURT OF JUSTICE. 2014. 31 March. Whaling in the Antarctic Australia v. Japan: New Zealand intervening: mérits. Disponível em: <http://www.CIJ-cij.org/docket/index.php?p $1=3 \& \mathrm{p} 2=3 \& \mathrm{k}=64 \& \mathrm{case}=148 \& \operatorname{code}=\mathrm{aj} \& \mathrm{p} 3=4>$. Acesso em: 20 dez. 2014>. Acesso em: 20 dez. 2014. p. 62-65.

53 INTERNATIONAL COURT OF JUSTICE. 2014. 31 March. Whaling in the Antarctic Australia v. Japan: New Zealand intervening: mérits. Disponível em: <http://www.CIJ-cij.org/docket/index.php?p $1=3 \& \mathrm{p} 2=3 \& \mathrm{k}=64 \&$ case $=148 \& \operatorname{code}=\mathrm{aj} \& \mathrm{p} 3=4>$. Acesso em: 20 dez. 2014. p. 66.

54 INTERNATIONAL COURT OF JUSTICE. 2014. 31 March. Whaling in the Antarctic Australia v. Japan: New Zealand intervening: dissenting opinion of judge Owada. Disponível em: <http://www.CIJcij.org/docket/files/148/18138.pdf>. Acesso em: 20 dez. 2014. p. 14. mento como "pesca com fins comerciais". 55

Ora, essa conclusão, além de ter se amparado em uma distinção artificial, como já argumentado acima, criou nova modalidade de classificação para atividades que realizem pesca a baleias, haja vista que, segundo a IWC somente existiriam três modalidades: para fins científicos, para fins comerciais e para subsistência de grupos aborígenes. De outra sorte, o simples fato do Projeto JARPA II necessitar de adequações técnicas e conter imprecisões não desnatura juridicamente seu caráter e sua finalidade científica, cabendo somente ao IWC e a seu Comitê Científico apreciarem as questões de caráter técnico que necessitam serem redesenhadas a fim de compatibilizá-las com a proteção ao meio ambiente marinho, proposta pela ICRW e nos demais instrumentos internacionais referentes ao tema. ${ }^{56} \mathrm{Nessa}$ mesma linha, Watkins havia se manifestado, antes do julgamento, que "mesmo existindo um desacordo sobre os métodos científicos [utilizados no JARPA II] e se e em que medida amostras letais deveriam ser utilizadas, seria inapropriado para a CIJ tentar resolver uma disputa científica no âmbito da IWC". ${ }^{57}$

Em sentido semelhante, os Juízes Abraham e Bennouna manifestaram-se, em seus votos divergentes, que:

29. A presunção de boa-fé não é absoluta, observação que não é suficiente para levar à conclusão da Corte, a saber, que as permissões especiais expedidas pelo Japão ao projeto JARPA II

55 INTERNATIONAL COURT OF JUSTICE. 2014. 31 March. Whaling in the Antarctic Australia v. Japan: New Zealand intervening: mérits. Disponível em: <http://www.CIJ-cij.org/docket/index.php?p $1=3 \& \mathrm{p} 2=3 \& \mathrm{k}=64 \&$ case $=148 \& \operatorname{code}=\mathrm{aj} \& \mathrm{p} 3=4>$. Acesso em: 20 dez. 2014. p. 69.

56 INTERNATIONAL COURT OF JUSTICE. 2014. 31 March. Whaling in the Antarctic Australia v. Japan: New Zealand intervening: opinion dissidente de M. le Juge Abraham. Disponível em: <http:// www.CIJ-cij.org/docket/files/148/18138.pdf > . Acesso em: 20 jan. 2015. p. 10-11. INTERNATIONAL COURT OF JUSTICE. 2014. 31 March. Whaling in the Antarctic Australia v. Japan: New Zealand intervening: dissenting opinion of judge Owada. Disponível em: $<$ http:// www.CIJ-cij.org/docket/files/148/18138.pdf>. Acesso em: 20 dez. 2014. p. 14-15. INTERNATIONAL COURT OF JUSTICE. 2014. 31 March. Whaling in the Antarctic Australia v. Japan: New Zealand intervening: dissenting opinion of judge Yusuf. Disponível em: < http:// www.CIJ-cij.org/docket/files/148/18148.pdf>. Acesso em: 20 dez. 2014. p. 15-16. INTERNATIONAL COURT OF JUSTICE. 2014. 31 March. Whaling in the Antarctic Australia v. Japan: New Zealand intervening: dissenting opinion of judge Bennouna. Disponível em: $<$ http://www.CIJ-cij.org/docket/files/148/18144.pdf>. Acesso em: 20 jan. 2015. p. 06.

57 WATKINS, Casey. Whaling in the Antarctic: case analysis and suggestions for the future. New York International Law Review, v. 25, n. 2, p. 49-77, 2012. p. 68. 
não são "para fins de pesquisa científica".

Para embasar seriamente uma conclusão como essa, seria necessário, a meu ver, dispor de elementos muito sólidos, que não apareceram nos debates, e, ao contrário, foi com base em argumentos fracos, e talvez na simples dúvida, suposições e aproximações que a Corte julgou ser possível acolher os argumentos australianos. ${ }^{58}$

Infelizmente, a abordagem adotada pela maioria permanece um pouco impressionista, na medida em que se assenta essencialmente em informações, duvidas e suspeitas, baseadas em uma seleção de indicadores contidos no meio dos vários relatórios e estudos científicos. ${ }^{59}$

Outro ponto extremamente criticável no critério de exame adotado pela CIJ refere-se ao ônus da prova que foi invertido, sem que tenha havido manifestação expressa da Corte sobre o porquê de não presumir a boa-fé do Japão ou ao menos para explicar o motivo de pertencer ao demandado, e não à Austrália, o ônus de comprovar que a concepção e a implementação do Projeto JARPA II eram para fins científicos. Esse argumento também foi apresentado pelos Juízes Abraham e Owada em seus votos dissidentes ${ }^{60}$ e por parte da doutrina, a exemplo de Foster que afirma que "isso reflete um pouco a ideia de que a Corte pode de fato

58 “29. La présomption de bonne foi n'étant pas irréfragable, l'observation qui précède ne suffit certes pas à démontrer que la conclusion de la Cour, à savoir que les permis spéciaux délivrés par le Japon dans le cadre de JARPA II ne l'ont pas été «en vue de recherches scientifiques», est erronée. Mais pour fonder sérieusement une telle conclusion, il aurait fallu, selon moi, disposer d'éléments particulièrement solides, que les débats n'ont pas fait apparaitre, et c'est au contraire sur la base de faibles arguments, et parfois de simples doutes, suppositions ou approximations, que la Cour a cru pouvoir accueillir les prétentions de l'Australie" (INTERNATIONAL COURT OF JUSTICE. 2014. 31 March. Whaling in the Antarctic Australia v. Japan: New Zealand intervening: opinion dissidente de M. le Juge Abraham. Disponível em: <http://www.CIJ-cij.org/docket/files/148/18138. pdf>. Acesso em: 20 jan. 2015. p. 07).

59 "Unfortunately, the approach adopted by the majority remains somewhat "impressionistic", inasmuch as it rests essentially on queries, doubts and suspicions, based on a selection of indicators from among the mass of reports and scientific studies" INTERNATIONAL COURT OF JUSTICE. 2014. 31 March. Whaling in the Antarctic Australia v. Japan: New Zealand intervening: dissenting opinion of judge Bennouna. Disponível em: <http:/ / www.CIJ-cij.org/docket/files/148/18144.pdf>. Acesso em: 20 jan. 2015. p. 01.

60 INTERNATIONAL COURT OF JUSTICE. 2014. 31 March. Whaling in the Antarctic Australia v. Japan: New Zealand intervening: opinion dissidente de M. le Juge Abraham. Disponível em: <http:// www.CIJ-cij.org/docket/files/148/18138.pdf>. Acesso em: 20 jan. 2015. p. 07. INTERNATIONAL COURT OF JUSTICE. 2014. 31 March. Whaling in the Antarctic Australia v. Japan: New Zealand intervening: dissenting opinion of judge Owada. Disponível em: <http:// www.CIJ-cij.org/docket/files/148/18138.pdf>. Acesso em: 20 dez. 2014. p. 14. ter se inclinado para enquadrar o seu papel nesse caso como a 'revisora' da decisão do Japão, ao invés de 'julgar' a questão do cumprimento pelo Japão dos termos da ICRW, e de fato considerou que esse papel envolve afastar as regras habituais sobre ônus da prova". ${ }^{61}$

Da mesma forma, o princípio da razoabilidade foi interpretado de nova forma, não cabendo ao demandante provar que a expedição da licença especial seguiu critérios desarrazoados, mas ao Japão demonstrar a razoabilidade da fundamentação estatal. Caso o mesmo critério seja utilizado em outras ocasiões, poder-se-ia estar diante de uma forma de controle da vontade Estatal - o que, talvez, pudesse resultar em posicionar o ônus da prova à luz do princípio da precaução, tal qual defendido por Foster. ${ }^{62}$

Não se ignora a farta literatura que demonstra os esforços do Japão para controlar a atuação da IWC e para por fim às manifestações da sociedade civil e de ONGs, nem mesmo se ignora a existência de resoluções do Comitê Científico e da IWC, questionando o uso de métodos letais nas pesquisas científicas e o aumento do número de amostras requeridas. ${ }^{63}$ No entanto, com base nos apontamentos contidos nos votos divergentes e de parte da doutrina que analisou criticamente o caso, observa-se que a metodologia do "critério de exame" ou standard of review não foi a mais interessante e efetiva,

61 FOSTER, Caroline. Motivations and methodologies: was Japan's Whaling programme for purposes of scientific research? In: SIMPÓSIO WHALING IN THE ANTARCTIC: THE ICJ JUDGMENT AND ITS IMPLICATION, 2014, Kobe. Presentation Files and Papers... Kobe: Kobe University, 2014. Disponível em: <http:// www.edu.kobe-u.ac.jp/ilaw/en/whaling_docs/paper_Foster.pdf $>$. Acesso em: 10 jan. 2015. FOSTER, Caroline. International Adjudication: standard of review and burden of proof: Australia-Apples and whaling in the Antarctic. Review of European Community and International Environmental Law, v. 21, n. 2, p. 80-91, 2012. Disponível em: $<$ http://www.law.auckland.ac.nz/people/c-foster>. Acesso em: 10 jun. 2015. p. 88-90.

62 FOSTER, Caroline. Motivations and methodologies: was Japan's Whaling programme for purposes of scientific research? In: SIMPÓSIO WHALING IN THE ANTARCTIC: THE ICJ JUDGMENT AND ITS IMPLICATION, 2014, Kobe. Presentation Files and Papers... Kobe: Kobe University, 2014. Disponível em: <http:/ / www.edu.kobe-u.ac.jp/ilaw/en/whaling_docs/paper_Foster.pdf $>$. Acesso em: 10 jan. 2015.

63 TEULINGS, Jasper. Peaceful protests against whaling on the high seas: a human rights-based approach. In: SYMMONS, Clive R. (Ed.). Selected contemporary issues in the law of the sea. Netherland: M. Nijhoff, 2011. v. 68. p. 221-248. p. 222. ANTON, Donald K. Dispute concerning Japan's JARPA II program of 'scientific whaling' (Australia v. Japan): a backgrounder. ANU College of Law Research Paper, n. 33-10, 2010. Disponível em: <http://ssrn.com/abstract $=1632722>$. Acesso em: 10 jan. 2015. p. 06. 
pois deu margem a críticas procedimentais e materiais ao ter "criado" um critério de análise sobre a finalidade de uma pesquisa científica. Ademais, a ferramenta metodológica também particularizou bastante os elementos analisados, de modo a dificultar com que o julgamento possa ser utilizado como precedente para estimular o fim da pesca às baleias em países como Noruega e Islândia. Até mesmo em relação ao Japão, observa-se que, em sendo realizadas revisões ao Projeto JARPA II, adequando-o a critérios com fundamentação estatal coerente, seria perfeitamente possível ao país apresentar novo plano de pesquisa científica à IWC e conseguir nova licença para pesca às baleias. Logo, a CIJ, apesar de ter inovado ao utilizar nova metodologia de análise, absteve-se de adotar uma interpretação sistêmica em relação à adoção da construção já empreendida por outros tratados e tribunais em relação à pesquisa científica marinha, fato que impossibilitou uma atuação protetiva ao meio ambiente marinho.

\section{Considerações finais}

A Corte Internacional de Justiça é mundialmente reconhecida por seus julgamentos vinculantes e pela influência que suas construções jurídicas têm na condução da política externa dos países. Diante dessa constatação, é essencial que todas as suas decisões sejam embasadas em argumentos jurídicos robustos e de difícil refutação.

Diante do exposto, observa-se que no caso Whaling in the Antartic (Australia vs. Japan, New Zeland Intervening) foi empregada a metodologia de critério de exame, já utilizada em âmbito da OMC. Com base nesta, a análise sobre a legalidade da concessão da licença especial, nos moldes do artigo VIII da ICRW foi realizado em duas grandes etapas. Na primeira, a CIJ analisou se as atividades desenvolvidas no bojo do Projeto JARPA II envolvem pesquisa científica. Na oportunidade, a Corte absteve-se de criar uma definição de pesquisa científica marinha, utilizar outra extrínseca existente ou mesmo de aplicar princípios e/ou parâmetros interpretativos extrínsecos que pudessem esclarecer quais elementos devem ou não devem estar presentes em uma pesquisa científica marinha.

$\mathrm{Na}$ segunda etapa, a CIJ avaliou se as atividades desenvolvidas no bojo do Projeto JARPA II são "para fins de" pesquisa científica. Para tal, a concepção e imple- mentação do projeto foram analisadas nos seguintes critérios: a utilização de métodos letais; a quantidade de amostras letais utilizadas; a metodologia utilizada para selecionar a quantidade das amostras; uma comparação entre a quantidade de amostras previstas e a quantidade efetivamente capturada; prazo previsto para duração; a produção científica gerada pelo programa; e o grau de cooperação do projeto com outros semelhantes.

Conforme restou demonstrado, a estratégia de análise escolhida pelo Tribunal não foi efetiva, pois gerou argumentos confusos (pautados em critérios externos à Convenção, divisão da análise da classificação em pesquisa em duas fases); incoerentes (inversão não expressa do ônus da prova, supressão do principio da boa-fé) e questionáveis (necessidade de comprovar a razoabilidade de uma decisão estatal). O que, ao contrário de proporcionar maior segurança jurídica e proteção à biodiversidade marinha, gerará insegurança e oportunizará a permanência da atividade de pesca às baleias.

De fato, segundo aponta CLAPHAM, no dia 18 de abril de 2014 — portanto, logo após o julgamento o Ministro da Agricultura do Japão anunciou que iria apresentar ao IWC um projeto para novo programa de pesquisa para as baleias da Antártida e também que iria continuar a operar o Projeto JARPA II, somente realizando algumas adequações, como reduzir o número de amostras de baleias. ${ }^{64}$

Nesse ínterim, apesar da grande exultação com que a Austrália, Nova Zelândia e as ONGs e movimentos sociais que militam a favor da proteção da biodiversidade marinha receberam o resultado do julgamento, pouco irá mudar na condução da política japonesa em relação ao tratamento da pesca às baleias, pois o critério metodológico de análise escolhido pela CIJ foi particularista e preocupou-se em apontar os erros e inexatidões do JARPA II, ao invés de ter estabelecido (ou cristalizado) critérios, ao menos normativos e políticos, que pudessem nortear a classificação de uma pesquisa como tendo finalidade científica ou comercial. Em verdade, entende-se ainda que, seguindo os argumentos expostos pelo juiz Bhandari, haveriam sim elementos aptos a concluir que o projeto teria finalidade comercial, ${ }^{65}$ o que levaria

64 CLAPHAM, Phillip J. Japan's whaling following the International Court of Justice ruling: brave new world - Or business as usual? Marine Policy, v. 51, p. 238-241, Jan. 2015.

65 INTERNATIONAL COURT OF JUSTICE. 2014. 31 March. Whaling in the Antarctic Australia v. Japan: New Zealand intervening: separate opinion of judge Bhandari. Disponível em: <http://www.icj- 
a uma argumentação mais coerente e, caso o Japão ainda buscasse realizar pesquisa científica com baleias, teria que realizar mudanças estruturais em seu projeto.

Num contexto mais geral ainda, englobando países como a Noruega e Groelândia, que igualmente ainda pescam baleias para fins comerciais e não são parte do cronograma da ICRW, o emprego dos princípios estabelecidos na UNCLOS para pesquisa científica marinha pela CIJ ou das construções normativas empreendidas por outros tratados e tribunais seria mais efetivo para consolidar no sistema jurídico uma noção sobre pesquisa científica marinha e, dessa forma, fortalecer a proteção à biodiversidade marinha.

\section{REFERÊNCIAS}

ANTON, Donald K. Dispute concerning Japan's JARPA II program of 'scientific whaling' (Australia v. Japan): a backgrounder. ANU College of Law Research Paper, n. 33-10, 2010. Disponível em: <http://ssrn.com/ abstract $=1632722>$. Acesso em: 10 jan. 2015.

ARON, William; BURKE, William; FREEMAN, Milton. Scientists versus whaling: science, advocacy, and errors of judgment. Bioscience, v. 52, n. 12, p. 1137-1140, 2002.

CLAPHAM, Phillip J. Japan's whaling following the International Court of Justice ruling: brave new world Or business as usual? Marine Policy, v. 51, p. 238-241, Jan. 2015.

DAI, Tamada. Unfavourable but unavoidable procedures: procedural aspects of the whaling case. In: SIMPÓSIO WHALING IN THE ANTARCTIC: THE ICJ JUDGMENT AND ITS IMPLICATION, 2014, Kobe. Presentation Files and Papers... Kobe: Kobe University, 2014. Disponível em: <http://www.edu.kobe-u. ac.jp/ilaw/en/whaling_sympo2014.html>. Acesso em: 10 jan. 2015.

FOSTER, Caroline. International Adjudication - standard of review and burden of proof: Australia-Apples and whaling in the Antarctic. Review of European Community and International Environmental Law, v. 21, n. 2, p. 8091, 2012. Disponível em: <http://www.law.auckland. ac.nz/people/c-foster>. Acesso em: 10 jun. 2015

cij.org/docket/files/148/18156.pdf>. Acesso em: 20 jan. 2015. p. 05-11.
FOSTER, Caroline. Motivations and methodologies: was Japan's Whaling programme for purposes of scientific research? In: SIMPÓSIO WHALING IN THE ANTARCTIC: THE ICJ JUDGMENT AND ITS IMPLICATION, 2014, Kobe. Presentation Files and Papers... Kobe: Kobe University, 2014. Disponível em: <http:/ / www.edu.kobe-u.ac.jp/ilaw/en/whaling_docs/paper_ Foster.pdf>. Acesso em: 10 jan. 2015.

FOSTER, Caroline. Public opinion and the interpretation of the World Trade Organisation's Agreement on Sanitary and Phytos Anitary Measures. Journal of International Economic Law, v. 11, n. 2, p. 427-458, Fev. 2008. Disponível em: <http://jiel.oxfordjournals.org>. Acesso em: 10 maio 2015. doi: 10.1093/jie 1/jgn011.

INTERNATIONAL COURT OF JUSTICE. 2014. 31 March. Whaling in the Antarctic Australia v. Japan: New Zealand intervening: dissenting opinion of judge Bennouna. Disponível em: <http://www.CIJ-cij.org/docket/ files/148/18144.pdf>. Acesso em: 20 jan. 2015.

INTERNATIONAL COURT OF JUSTICE. 2014. 31 March. Whaling in the Antarctic Australia v. Japan: New Zealand intervening: dissenting opinion of judge Owada. Disponível em: <http://www.CIJ-cij.org/docket/files/148/18138.pdf>. Acesso em: 20 dez. 2014.

INTERNATIONAL COURT OF JUSTICE. 2014. 31 March. Whaling in the Antarctic Australia v. Japan: New Zealand intervening: dissenting opinion of judge Yusuf. Disponível em: <http://www.CIJ-cij.org/docket/files/148/18148.pdf>. Acesso em: 20 dez. 2014.

INTERNATIONAL COURT OF JUSTICE. 2014. 31 March. Whaling in the Antarctic Australia v. Japan: New Zealand intervening: mérits. Disponível em: <http://www. CIJ-cij.org/docket $/$ index.php?p1 $=3 \& p 2=3 \& \mathrm{k}=64 \& \mathrm{c}$ ase $=148 \&$ code $=$ aj\&p3 $=4>$. Acesso em: 20 dez. 2014.

INTERNATIONAL COURT OF JUSTICE. 2014. 31 March. Whaling in the Antarctic Australia v. Japan: New Zealand intervening: opinion dissidente de M. le Juge Abraham. Disponível em: <http://www.CIJ-cij.org/docket/ files/148/18138.pdf>. Acesso em: 20 jan. 2015.

INTERNATIONAL COURT OF JUSTICE. 2014. 31 March. Whaling in the Antarctic Australia v. Japan: New Zealand intervening: separate opinion of judge Bhandari. Disponível em: <http://www.icj-cij.org/docket/files/148/18156.pdf>. Acesso em: 20 jan. 2015.

INTERNATIONAL COURT OF JUSTICE. 2014. 
31 March. Whaling in the Antarctic Australia v. Japan: New Zealand intervening: separate opinion of judge Cançado Trindade. Disponível em: < http://www.CIJ-cij.org/docket/files/148/18146.pdf>. Acesso em: 20 jan. 2015.

INTERNATIONAL WHALING COMMISSION. International Convention for the Regulation of Whaling. Washington, 2 December, 1946. Disponível em: <https:// archive.iwc.int $/$ pages $/$ view.php?ref $=3607 \& \mathrm{k}=>$. Acesso em: 20 jan. 2015.

INTERNATIONAL WHALING COMMISSION. International Convention for the Regulation of Whaling. September 1946. Schedule, as amended by the Commission at the 64th Annual Meeting Panama City. Panama, July 2012. Disponível em: <https://archive.iwc.int/pages/ view.php?ref=3606\&k=> . Acesso em: 20 jan. 2015.

MATZ-LÜCK, Nele. Norm interpretation across international regimes: competences and legitimacy. In: YOUNG, Margaret (Org.). Regime interaction in international law: facing fragmentation. Cambridge: Cambridge University Press, 2012. p. 201-234.

SAKAI, Hironobu. After the whaling case: its lessons from a japanese perspective. In: WHALING IN THE ANTARCTIC: THE ICJ JUDGMENT AND ITS IMPLICATION, 2014, Kyoto. Paper... Kyoto: Kyoto University, 2014. Disponível em: <http://www.edu.kobe-u. ac.jp/ilaw/en/whaling_docs/paper_Sakai.pdf $>$. Acesso em: 20 jan. 2015.

SANDS, Philippe. Principles of international environmental law. 2. ed. Cambridge: Cambridge University Press,
2003.

TANAKA, Yoshifumi. The international law of the sea. Cambridge: Cambridge University Press, 2012.

TEULINGS, Jasper. Peaceful protests against whaling on the high seas: a human rights-based approach. In: SYMMONS, Clive R. (Ed.). Selected contemporary issues in the law of the sea. Netherland: M. Nijhoff, 2011. v. 68. p. 221-248.

UNITED NATIONS Environment Programme. Study of the relationship between the Convention on Biological Diversity and the United Nations Convention on the Law of the Sea with regard to the conservation and sustainable use of genetic resources on the deep seabed (decision II/10 of the Conference of the Parties to the Convention on Biological Diversity). Disponivel em: <https://www.cbd.int/doc/meetings/sbstta/sbstta-08/information/sbstta-08-inf-03-rev1-en.doc $>$. Acesso em: 24 out. 2014.

UNITED NATIONS. Division for Ocean Affairs and the Law of the Sea Office of Legal Affairs. Marine scientific research: a revised guide to the implementation of the relevant provisions of the United Nations Convention on the Law of the Sea. New York, 2010.

UNITED NATIONS. Montego Bay Convention. Disponível em: <http://www.un.org/Depts//los/convention_agreements/texts/unclos/unclos_e.pdf $>$. Acesso em: 20 nov. 2014.

WATKINS, Casey. Whaling in the Antarctic: case analysis and suggestions for the future. New York International Law Review, v. 25, n. 2, p. 49-77, 2012. 
Para publicar na Revista de Direito Internacional, acesse o endereço eletrônico www.rdi.uniceub.br ou www.brazilianjournal.org.

Observe as normas de publicação, para facilitar e agilizar o trabalho de edição. 